\title{
Immunization with Bivalent Flagellin Protects Mice against Fatal Pseudomonas aeruginosa Pneumonia
}

\author{
Bahador Behrouz, ${ }^{1}$ Farhad B. Hashemi, ${ }^{2}$ Mohammad Javad Fatemi, ${ }^{3}$ Sara Naghavi, ${ }^{4}$ \\ Gholamreza Irajian, ${ }^{5}$ Raheleh Halabian, ${ }^{1}$ and Abbas Ali Imani Fooladi ${ }^{1}$ \\ ${ }^{1}$ Applied Microbiology Research Center, Baqiyatallah University of Medical Sciences, Tehran, Iran \\ ${ }^{2}$ Department of Microbiology, School of Medicine, Tehran University of Medical Sciences, Tehran, Iran \\ ${ }^{3}$ Burn Research Center, Hazrat Fatima Hospital, Iran University of Medical Sciences, Tehran, Iran \\ ${ }^{4}$ Department of Bacteriology, Faculty of Medical Sciences, Tarbiat Modares University, Tehran, Iran \\ ${ }^{5}$ Department of Microbiology, School of Medicine, Iran University of Medical Sciences, Tehran, Iran \\ Correspondence should be addressed to Abbas Ali Imani Fooladi; imanifouladi.a@gmail.com
}

Received 6 January 2017; Revised 25 August 2017; Accepted 10 September 2017; Published 19 October 2017

Academic Editor: Peirong Jiao

Copyright (C) 2017 Bahador Behrouz et al. This is an open access article distributed under the Creative Commons Attribution License, which permits unrestricted use, distribution, and reproduction in any medium, provided the original work is properly cited.

\begin{abstract}
Pseudomonas aeruginosa lung infections present a major challenge to healthcare systems worldwide because they are commonly associated with high morbidity and mortality. Here, we demonstrate the protective efficacy of type a and b flagellins (bivalent flagellin) against acute fatal pneumonia in mice. Mice immunized intranasally with a bivalent flagellin vaccine were challenged by different flagellated strains of $P$. aeruginosa in an acute pneumonia model. Besides the protective effect of the vaccine, we further measured the host innate and cellular immunity responses. The immunized mice in our study were protected against both strains. Remarkably, active immunization with type a or b flagellin significantly improved survival of mice against heterologous strain compared to flagellin a or b antisera. We also showed that after an intranasal challenge by $P$. aeruginosa strain, neutrophils are recruited to the airways of vaccinated mice, and that the bivalent flagellin vaccine was proved to be protective by the generated $\mathrm{CD} 4^{+} \mathrm{IL}-17^{+}$Th17 cells. In conclusion, bivalent flagellin vaccine can confer protection against different strains of $P$. aeruginosa in an acute pneumonia mouse model by eliciting effective cellular and humoral immune responses, including increased IL-17 production and improved opsonophagocytic killing.
\end{abstract}

\section{Introduction}

Pseudomonas aeruginosa pulmonary infection as a lifethreatening complication frequently causes bacteremia and sepsis in hospitalized and immunocompromised patients $[1,2]$. Moreover, the widespread and empirical use of broad-spectrum antibiotics in critical care units has led to the continuous emergence of multidrugresistant (MDR) P. aeruginosa strains that present a major challenge to clinical therapy and contribute significantly to increased morbidity and mortality [3]. The high mortality and prevalence of infection with MDR $P$. aeruginosa strains accompanied by the paucity of new effective antibiotic classes present unique challenges to clinicians and highlight the necessity for designing new treatment approaches, such as immunotherapy, which targets pathogen-specific virulence factors to reduce pathogenesis without inducing multidrug resistance $[4,5]$. Moreover, the complexity of the $P$. aeruginosa genome, which encodes numerous antigens, indicates that immunotherapy using a single antigen will not provide sufficient protection.

To date, most $P$. aeruginosa vaccines focusing on immunization and treatment targeting pseudomonal virulence factors, such as LPS O antigen [6], the outer membrane proteins $\mathrm{F}$ and I [7], or the type III secretion system component PcrV [8], have been described in the literature as having conventional protective mechanisms, namely, antibody-mediated opsonophagocytic killing and/ or antibody-mediated toxin inhibition. Recently, studies have shown that Th17 cells are critical for providing 
protection against $P$. aeruginosa pneumonia via rapid recruitment of neutrophils to the airways in the absence of opsonophagocytic antibody $[9,10]$. These findings suggest that an effective vaccine for providing full-fledged protection against various $P$. aeruginosa infections in different tissues can induce multiple cellular and humoral effectors.

Most clinical isolates of $P$. aeruginosa are motile with the aid of a single polar flagellum, which is essential for systemic spread throughout the organs from the initial site of colonization [11]. Flagellin is the primary protein component of the flagella, which is classified into two distinct serotypes a and $b$ [12]. Furthermore, the conserved domains of flagellin are strongly antigenic and serve as a pathogen-associated molecular pattern (PAMP) that induce a strong NF $\kappa$ B-mediated inflammatory response via toll-like receptor 5 (TLR5) signal transduction [13]. Several studies have shown the strong immunogenicity of flagellin initiates a general recruitment of both $\mathrm{T}$ and $\mathrm{B}$ cells to secondary lymphoid sites, eliciting TLR5 ${ }^{+}, \mathrm{CD}_{11 \mathrm{c}^{+}}$, and T cell-like similar antigen recognition $[14,15]$. Due to TLR5 agonist activity of flagellin, they play an important role as potent adjuvants to enhance protective humoral responses $[15,16]$. Several in vivo studies not only have demonstrated the importance of flagellins as a crucial virulence factor contributing to the pathogenesis of lung infections but also validated them as target antigens for immunization [17-22]. Immunization with type $a$ or $b$ flagellin provided protection against lung infections [23], keratitis [24], urinary tract, and burn wound infections [25]. These studies have confirmed that protection provided by flagellin is highly type specific and the presence of both types of flagellin is crucial. The results of our recent studies $[20,26]$ demonstrating protection provided by flagellin in $P$. aeruginosa burn infection via induction of IL-17 encouraged us to study active and passive immunization strategies using bivalent flagellin in order to provide fullfledged protection against various $P$. aeruginosa clinical isolates in the acute fatal pneumonia model.

\section{Materials and Methods}

2.1. Bacterial Strains. P. aeruginosa strains PAK and PAO1 were used for the purification of type $a$ and $b$ flagellin proteins, respectively.

2.2. Animals. Female 6-8-week-old BALB/C mice were purchased from Pasteur Institute (Tehran, Iran). All animal experiments were complied with institutional animal care committee (IACC) guidelines regarding the use of animals in research.

2.3. Preparation of Recombinant Proteins. Recombinant type $\mathrm{a}$ and $\mathrm{b}$ flagellin proteins were purified from $E$. coli BL21 (DE3) carrying pET-28a vector as previously described [27, 28].

2.4. Immunization of Mice. Mice were immunized intranasally (i.n.) as described previously. Briefly, mice were anesthetized by mixture of ketamine $(6.7 \mathrm{mg} / \mathrm{ml})$ and xylazine $(1.3 \mathrm{mg} / \mathrm{ml})$ and then immunized by placing $10 \mu \mathrm{l}$ of mixed flagellins ( $1 \mu \mathrm{g}$ of each flagellin), or flagellin a $(2 \mu \mathrm{g})$, or flagellin b (2 $\mu \mathrm{g})$, or PBS on each nostril at weekly intervals. In several published $P$. aeruginosa vaccine studies, PBS has been used as a control $[9,29-31]$. At day 42, mice were challenged i.n. with $2 \times 10^{7} \mathrm{CFU}$ of $P$. aeruginosa strains directly into each nostril, as described previously [23]. In addition, five mice from each group were sacrificed $24 \mathrm{~h}$ after infection. Then the lung, liver, blood, and spleen were harvested for bacterial load enumeration. Bronchoalveolar lavage fluid (BALF) was collected 6 and $18 \mathrm{~h}$ after infection for quantitation of CFU, neutrophils, and IL-17 cytokine. For passive immunization, mice were injected intraperitonealy (i.p.) with $200 \mu \mathrm{l}$ of antibodies raised to bivalent flagellin, or flagellin a, or flagellin $\mathrm{b} 12 \mathrm{~h}$ before and after challenge. All mice were closely monitored for one week.

2.5. Enzyme-Linked Immunosorbent Assay (ELISA). To determine the levels of specific antibodies (total IgG, IgG1, and IgG2a) in mouse sera, ELISA was performed with plates coated with a whole live cell of $P$. aeruginosa strains PAK or PAO1 or mixed flagellins as described previously [20]. Briefly, $100 \mu \mathrm{l}$ of either P. aeruginosa strains PAK or PAO1 or mixed flagellins was incubated overnight at $4^{\circ} \mathrm{C}$, washed with $0.5 \%$ Tween-PBS (T-PBS), and blocked with PBS $+3 \%$ bovine serum albumin (Sigma-Aldrich). Indicated dilutions of sera from immunized mice were incubated overnight at $4^{\circ} \mathrm{C}$ and washed $3 \mathrm{x}$ with T-PBS, and $100 \mu \mathrm{l}$ of $1: 7000$-diluted horseradish peroxidase-conjugated goat anti-mouse (HRP; Sigma-Aldrich) was incubated $(1 \mathrm{~h}, \mathrm{RT})$. Plates were then washed five times with T-PBS, and of TMB substrate (Sigma-Aldrich) was added ( $100 \mu \mathrm{l} /$ well; $30 \mathrm{~min}$. at RT). Concentrations of serum IgG1 and IgG2a subtypes against mixed flagellins were determined as described above, except that we used $100 \mu \mathrm{l} /$ well of IgG subtype-specific HRPconjugated secondary anti-mouse IgG1, or IgG2a antibody (Sigma-Aldrich) diluted 1:8000 in 0.5\% skim milk/T-PBS.

2.6. Cell Proliferation and Cytokine Measurements. For lymphocyte proliferation assays, ELISA plates were seeded with $1 \times 10^{5} \mathrm{~T}$ cells, $1 \times 10^{5}$ irradiated (1500 rad) splenocytes isolated from naïve mice as antigen-presenting cells (APCs), and $1 \mu \mathrm{g}$ of flagellin $\mathrm{a}$, or flagellin $\mathrm{b}$ as antigen, while other groups contained $1 \mu \mathrm{g}$ per well anti-CD4, anti-CD8, and rat IgG isotype (all are from BD Biosciences) antibody. The cells were all cultured in RPMI 1640 containing 10\% heatinactivated FBS. At $24 \mathrm{~h}$ and $72 \mathrm{~h}$ after incubation, T lymphocyte proliferation assay was carried out using 5-bromo-2deoxyuridine (BrdU; Roche, Germany) according to the manufacturer's protocol. At the same time, IL-17 levels were measured by examining cell-free culture supernatant fluid using specific ELISA assay (R\&D Systems).

2.7. Depletion of Immune Effectors. Immune cell subsets were depleted as described [32]. For in vivo CD4 or CD8 T cells, T cell depletion, CD4-specific mAb (GK1.5; BD PharMingen), or CD8-specific mAb (53-6.7; BD PharMingen) were administered both intranasally and intraperitoneally $(100 \mu \mathrm{g} / \mathrm{dose}$ and $500 \mu \mathrm{g} /$ dose, resp.) 72 and 24 hours before bacterial challenge. Depletion of the targeted cell types was confirmed by subsequent FACS analysis, which showed $>98 \%$ depletion 
of the respective cell type. Polyclonal antibody to murine IL17 was produced by immunizing rabbits at multiple intradermal sites with mouse recombinant IL-17 (R\&D Systems) mixed with CFA, as previously described [33]. Affinity chromatography (using protein $\mathrm{G}$ ) was used for the separation of anti-IL-17 IgG from the whole serum, according to the manufacturers' instructions (Thermo Fisher Scientific, USA). This antibody was specific for IL-17, as determined by ELISA, but did not cross-react IL-2, IFN- $\gamma$, IL-4, IL-10, IL-5, or IL-13. The control antibody used in these experiments was the IgG fraction from normal rabbit serum purified by protein $G$ affinity chromatography, as described above. IL-17 depletion studies were done using anti-IL$17 \mathrm{IgG}$ ( $1 \mathrm{mg}$ i.p.) or control $\operatorname{IgG}$ for 3 consecutive days before the mice were challenged by $P$. aeruginosa strains as described by Li et al. [34].

2.8. Opsonophagocytic Activity Assay. The assay was performed as described [20,25]. Briefly, assays were performed in a sterile microcentrifuge tube $100 \mu \mathrm{l}$ of each component, polymorphonuclear leukocytes (PMNs; $2 \times 10^{9}$ cells), $P$. aeruginosa strains $\left(5 \times 10^{7} \mathrm{CFUs}\right)$, infant rabbit serum, and diluted antibodies. Generally, $\geq 50 \%$ opsonic killing activity of immune serum is considered biologically significant [10].

2.9. Motility Inhibition Assay. Assays were performed as described $[20,25]$. Briefly, antibodies were added to motility agar (LB with $0.3 \%(w / v)$ agar) in 24-well plates (Greiner Bio-One, Germany). P. aeruginosa strains $\left(\mathrm{OD}_{600}=0.2\right)$ were added into the central well of each plate and incubated at $37^{\circ} \mathrm{C}$. Mean diameters of bacterial colonies with sharp and less distorted rings were measured after incubating for $18 \mathrm{~h}$.

2.10. Statistical Analysis. All statistical analyses were performed using GraphPad Prism 6 (GraphPad Software Inc., USA). Nonparametric data were analyzed by KruskalWallis followed by Dunn's multiple comparison tests. Parametric data were evaluated by ANOVA with Tukey's multiple comparison tests. All results were expressed as the mean \pm standard deviation (SD). The log-rank test was used to compare Kaplan-Meier between different treatment mouse groups. $P$ value of $<0.05$ was considered statistically significant.

\section{Result}

3.1. Protective Efficacy of Bivalent Flagellin Immunization. To determine the protective efficacy of the bivalent flagellin vaccine against $P$. aeruginosa strains, immunized mice were challenged i.n. with different flagellated strains of $P$. aeruginosa. As shown in Figures 1(a) and 1(b), nasal immunization with bivalent flagellin protected against lethal pneumonia due to PAK (100\% survival) and PAO1 (91.66\% survival) and survival rates were all significantly higher than those in mice administered with PBS $(P>0.01)$. Flagellin aimmunized mice were significantly protected $(P>0.05)$ from lethality after challenge with homologous strain PAK with a survival rate of $91.66 \%$, compared to $58.33 \%$ for heterologous strain PAO1 (Figures 1(c) and 1(d)). Nasal immunization with flagellin b leads to $83.33 \%$ protective effect for homologous strain PAO1 compared with $41.66 \%$ in the heterologous PAK challenge $(P>0.05$; Figures $1(\mathrm{e})$ and $1(\mathrm{f}))$. However, provided heterologous protection by flagellin a or flagellin $b$ immunization was significantly higher than that of the controls.

Moreover, we evaluated the efficacy of passive immunization with antisera from bivalent flagellin-, or flagellin a-, or flagellin $\mathrm{b}-$, or PBS-immunized mice against $P$. aeruginosa strains. Bivalent flagellin antisera completely protected mice from challenge with PAK ( $75 \%$ survival) and PAO1 (83.33\% survival; Figures 1(a) and 1(b)). Transfer of flagellin a antisera exhibited significant protective effect role against homologous strain PAK (83.33\% survival, $P<0.01)$ but only has a partial protective role against heterologous strain PAO1 (25\% survival, Figures 1(c) and 1(d)). Passive immunization with flagellin $b$ significantly protected immunized mice against homologous strain PAO1 $(75 \%$ survival, $P<0.01)$ compared with heterologous strain PAK (16.66\% survival, Figures 2(e) and 2(f)). However, provided heterologous protection by antisera to flagellin a or flagellin $b$ was significantly higher than that of the controls $(P<0.05$; Figures $1(\mathrm{c}), 1(\mathrm{~d})$, $1(\mathrm{e})$, and $1(\mathrm{f}))$.

\subsection{Opsonic Killing Activity of Bivalent Flagellin Immune} Sera. To test the functional activity of serum antibodies in the protection afforded by the bivalent flagellin vaccine, we evaluated the in vitro opsonic killing activity of pooled sera obtained from immunized mice 3 weeks after the third (final) nasal immunization. As shown in Figure 3, bivalent flagellin antisera at a dilution $1: 10$ significantly promoted the phagocytosis of $P$. aeruginosa strains PAK (82.70\%) and PAO1 (86.23\%) compared with that of serum isolated from control group mice $(P<0.01)$. Flagellin a antiserum in the immune serum showed significantly higher killing ability against homologous strain PAK $(78.61 \%, P<0.01)$ in comparison with PAO1 strain (33.56\%, Figure 3). Sera from flagellin bimmunized mice had significantly killing activity against homologous strain PAO1 (80.59\%, $P<0.01)$, comparable to that against heterologous strain PAK (24.27\%, Figure 3). However, the opsonic killing activity of flagellin a or flagellin $\mathrm{b}$ antisera against the heterologous strain was significantly higher than that of serum from control mice $(P<0.05)$.

\subsection{Antimotility Activity of Bivalent Flagellin Immune Sera.} We evaluated the functional activity of bivalent flagellin immune sera to inhibit the motility of different flagellated P. aeruginosa strains. As shown in Figures 4(a) and 4(b), bivalent flagellin immune sera at a dilution of $1: 300$ or less completely inhibited the motility of $P$. aeruginosa strains compared with the controls $(P<0.01)$. Antisera to flagellin a at dilution of $1: 300$ or less completely inhibited the motility of the homologous strain $(P<0.01)$, but there was some cross-reactivity with the heterologous strain $(P<0.05$; Figures 4(a) and 4(b)). Antibodies against flagellin $\mathrm{b}$ at dilution of 1:300 or less inhibited the motility of homologous strain PAO1 more significantly than heterologous strain PAK $(P<0.05$; Figures 4(a) and 4(b)). 


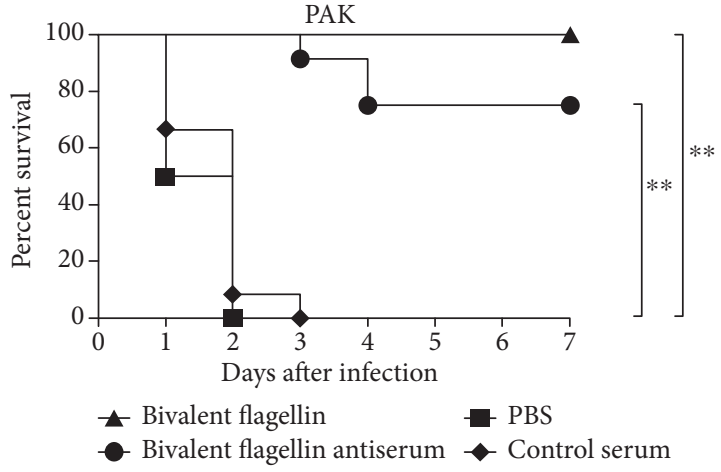

(a)

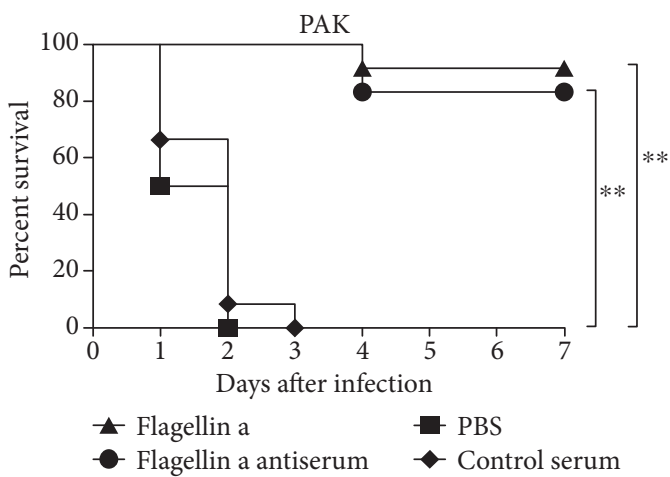

(c)

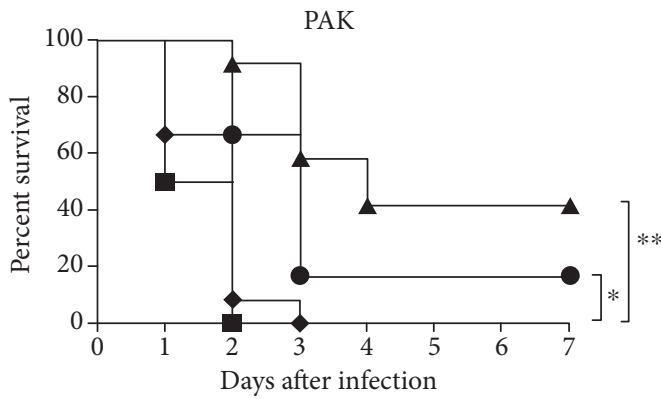

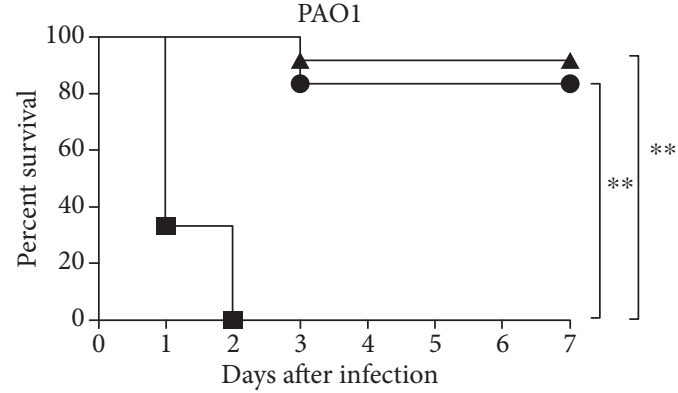

(b)

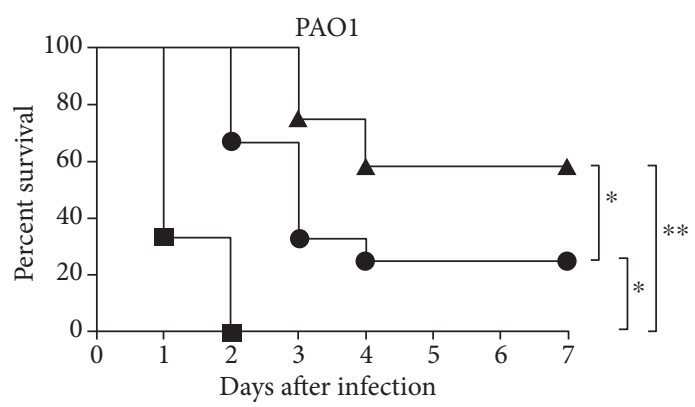

(d)

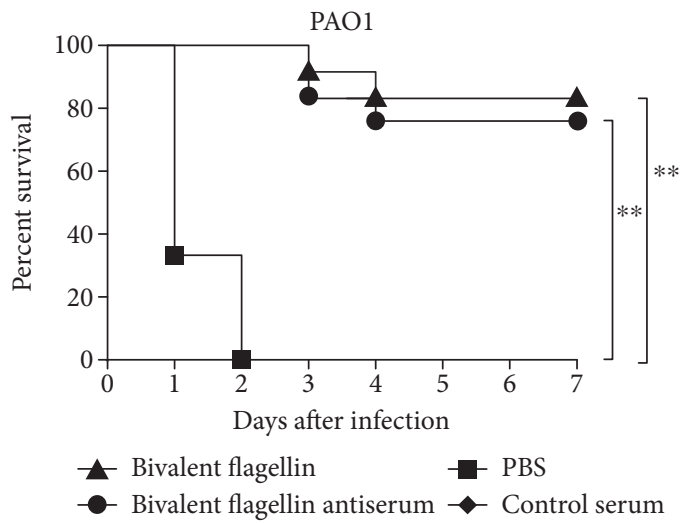

(f)

FIgURE 1: Survival rates of actively and passively immunized BALB/c mice ( $n=12$ mice/group) to infection with $P$. aeruginosa strains. Active and passive immunization against bivalent flagellin $(a, b)$, flagellin a $(c, d)$, and flagellin b (e, f). Kaplan-Meier curves were plotted for mice of the above groups, which were challenged by $2 \times 10^{7} \mathrm{CFUs}$ of $P$. aeruginosa strains PAO1 and PAK and monitored the seven day survival rates. ${ }^{*} P<0.05$ and ${ }^{* *} P<0.01$.

3.4. Specificity of Antibodies Raised against Bivalent Flagellin. To assess the humoral responses evoked by bivalent flagellin vaccine, we compared serum IgG levels among immunized mice challenged with either the PAK or PAO1 strain. While the prechallenge IgG levels of mice injected with bivalent flagellin against whole live cells of $P$. aeruginosa strains or mixed flagellins were similar, the serum IgG levels significantly increased after infection with PAK or PAO1 strains infection $(P<0.05$; Figures 5(a), 5(b), and 5(c)). IgG titer in sera from vaccinated mice with type a or b flagellin significantly increased after challenge with the homologous strain compared with that in heterologous strain of $P$. aeruginosa infection $(P<0.01$; Figures 5(a), 5(b), and 5(c)). Similar results were obtained when IgG1 subtype was examined (Figure 5(d)). Among bivalent flagellin-immunized mice, no significant differences in the titer increases for specific IgG2a subtypes against mixed flagellins were observed in pre- and postchallenge with $\mathrm{PAK}$ or PAO1, respectively $(P>0.05$; Figure 5(e)). IgG2a level in mice immunized with type a or b flagellin was significantly decreased after challenge with the heterologous strain compared with mice challenged with the heterologous strain $(P<0.05$; Figure 5(e)). The titer of antigen-specific antibodies induced by bivalent flagellin was similar to that induced 


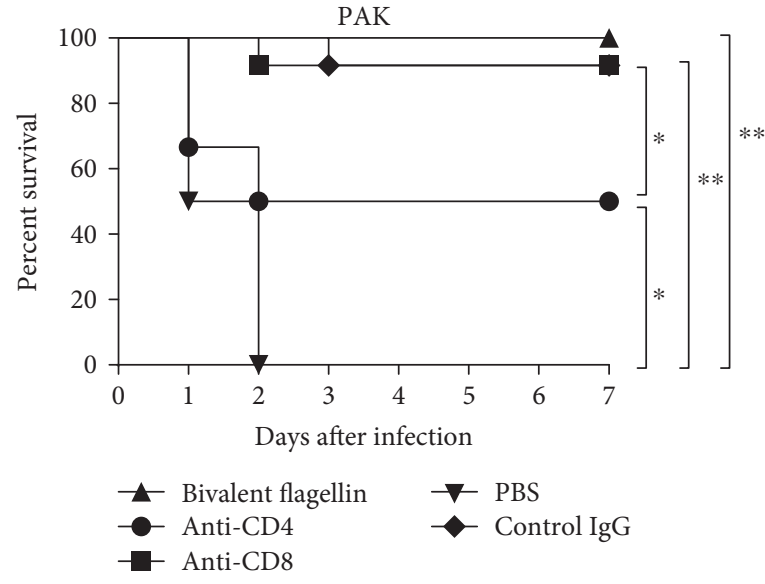

(a)

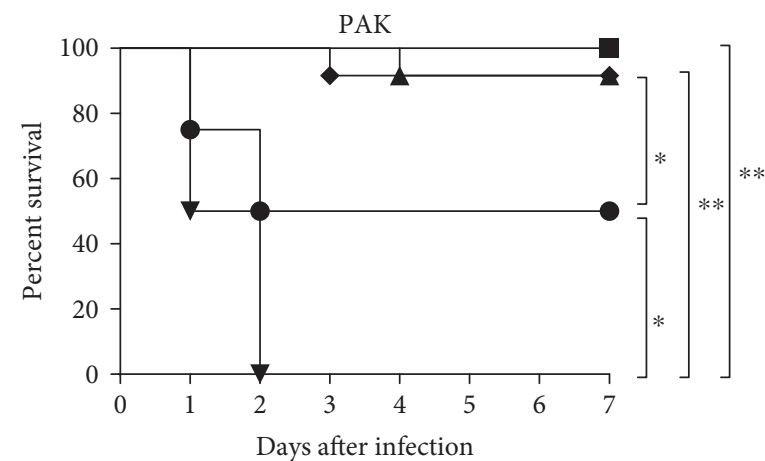

Days after infection

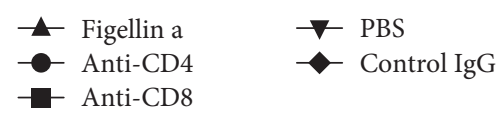

(c)

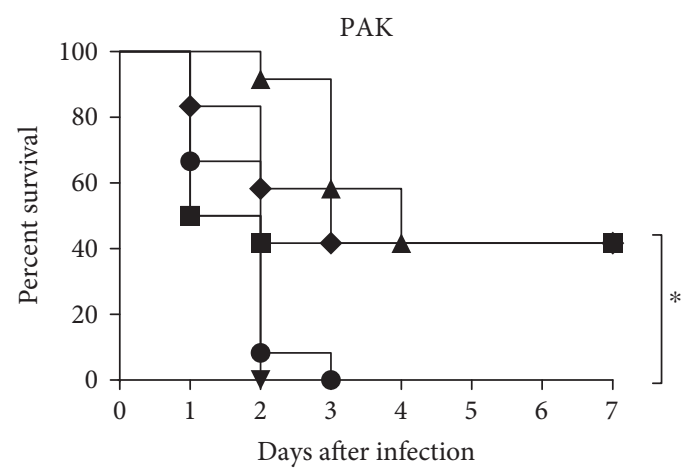

(e)

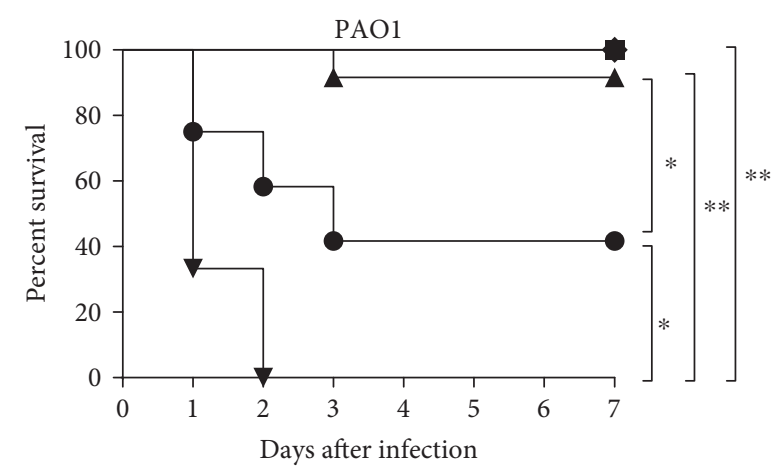

(b)

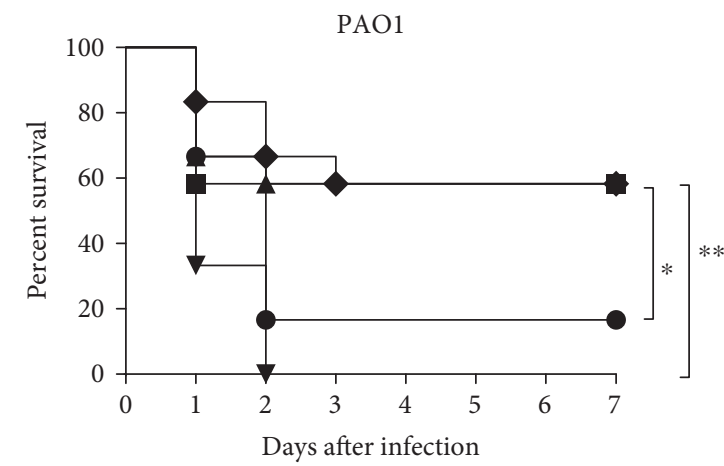

(d)

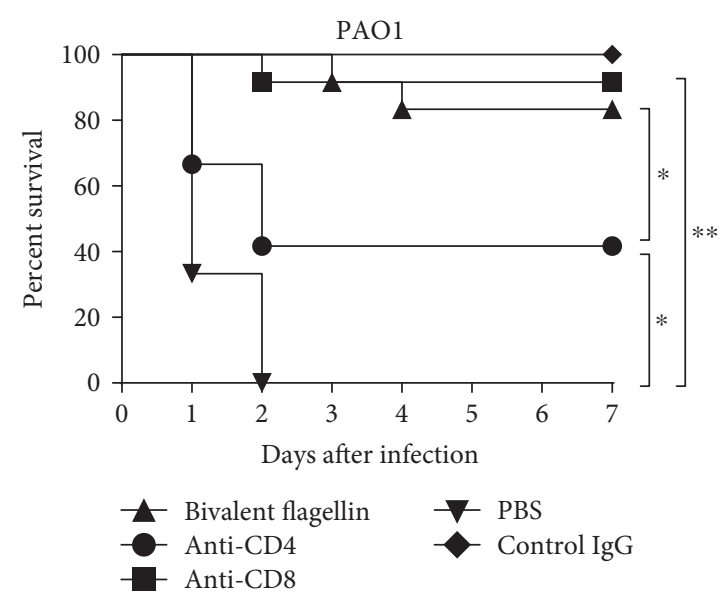

(f)

Figure 2: The protective role of $\mathrm{CD}^{+} \mathrm{T}$ lymphocytes in bivalent flagellin vaccine against $P$. aeruginosa strains. Bivalent flagellin- (a, b), flagellin a- (c, d), and flagellin b- $(\mathrm{e}, \mathrm{f})$ immunized mice $(n=12$ mice/group) were treated with either anti-CD8 monoclonal antibody, or anti-CD4 monoclonal antibody, or normal rat IgG and then were challenged with $2 \times 10^{7}$ CFUs of $P$. aeruginosa strains PAO1 and PAK. ${ }^{*} P<0.05$ and ${ }^{* *} P<0.01$. NS = nonsignificance.

by flagellin a or $b$, which indicated that there is no interference among each vaccine component in induction of protective antibodies (data not shown).
3.5. T Cell Responses Induced by Bivalent Flagellin Vaccine. To test whether vaccine candidates could induce lymphocyte proliferation, we analyzed the stimulation index of splenic $\mathrm{T}$ 


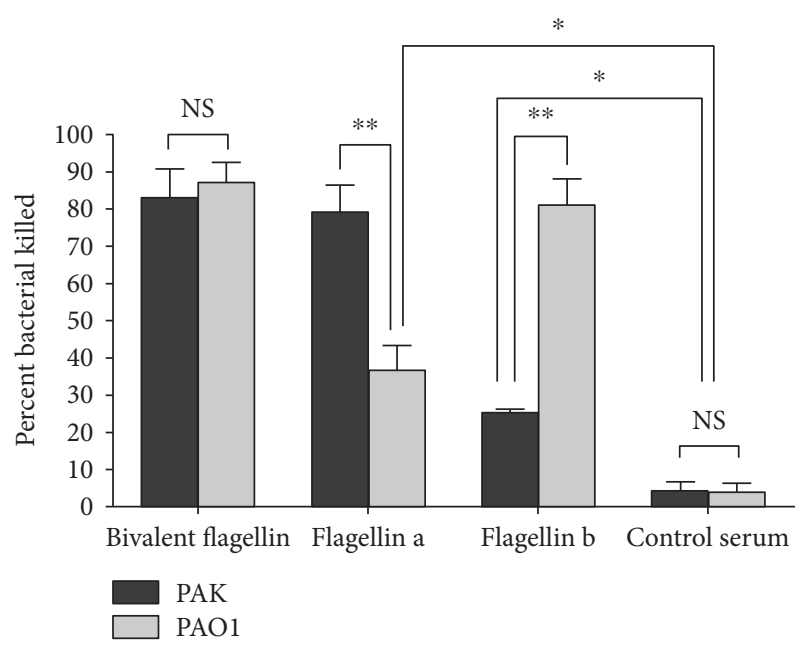

FIGURE 3: The opsonic killing activity of sera from bivalent flagellin-, flagellin a-, and flagellin b-immunized mice 3 weeks after the final immunization. Values presented as the mean of triplicate technical replicates \pm SD. ${ }^{*} P<0.05$ and ${ }^{* *} P<0.01$. NS $=$ nonsignificance.

cells from immunized mice. As shown in Figures 6(a) and 6(b), there was a higher proliferation level of bivalent flagellin immune $\mathrm{T}$ cells to either flagellin a or flagellin $\mathrm{b}$ at both 24 and $72 \mathrm{~h}$ when compared with $\mathrm{T}$ lymphocytes isolated from the controls $(P<0.01)$, which means vaccinated Tlymphocytes could be stimulated by both types of flagellin without interference. (Figures 6(a) and 6(b); $P<0.05$ ). The proliferation rate of flagellin $\mathrm{a}$ or $\mathrm{b}$ immune $\mathrm{T}$ cell cultures stimulated with the homologous antigen at both 24 and $72 \mathrm{~h}$ was significantly higher than the cultures stimulated with heterologous antigen (Figures 6(c) and 6(d) and Figures $6(\mathrm{e})$ and $6(\mathrm{f}) ; P<0.01)$. Additionally, the proliferation level of flagellin a or b immune $\mathrm{T}$ cell cultures stimulated with heterologous antigen was significantly higher than $\mathrm{T}$ cells from control mice (Figures 6(c) and 6(d) and Figures $6(\mathrm{e})$ and $6(\mathrm{f}) ; P<0.05)$.

In order to further distinguish whether $\mathrm{CD}^{+} \mathrm{T}$ lymphocytes were the immune cells involved in the anti-infection effect by bivalent flagellin vaccine in vivo, $\mathrm{CD} 4^{+}$or $\mathrm{CD} 8^{+} \mathrm{T}$ lymphocytes were depleted independently by corresponding antibodies as described above. We demonstrated that antiinfection activity with the bivalent flagellin immunization relatively abrogate in in vivo depletion of $\mathrm{CD}^{+} \mathrm{T}$ lymphocytes. After depletion of $\mathrm{CD}^{+} \mathrm{T}$ lymphocytes in the bivalent flagellin-immunized group, the survival rate decreased to $50 \%$ and $41.66 \%$ when infected with strain PAK and PAO1, respectively (Figures $2(\mathrm{a})$ and $2(\mathrm{~b})$ ). Also, the survival rate was not decreased compared to the control group when challenged by PAK (Figure 2(a)) and PAO1 (Figure 2(b)), since the killing ability of immune serum against $P$. aeruginosa strains was effective. Depletion of $\mathrm{CD} 4^{+} \mathrm{T}$ lymphocytes in flagellin a-immunized group decreased the survival rate to $50 \%$ and $16.16 \%$ when challenged with strain PAK and PAO1, respectively (Figures $2(\mathrm{c})$ and $2(\mathrm{~d})$ ). The survival rate of mice in flagellin b-immunized group after depletion of $\mathrm{CD} 4^{+} \mathrm{T}$ lymphocytes decreased to $41.66 \%$ and $0 \%$ when challenged with the strain PAO1 and PAK, respectively (Figures 2(e) and 2(f)). Depletion of $\mathrm{CD}^{+} \mathrm{T}$ lymphocytes showed no effect on the survival rate of immunized mice. Also, the treatment with normal rat IgG showed no effect on the survival rate.

3.6. Th17 Cells and IL-17 Were Activated by Bivalent Flagellin Vaccine. To test whether the bivalent flagellin vaccine could induce IL-17, we evaluated IL-17 production by the CD4 ${ }^{+}$ $\mathrm{T}$ cells recovered from immunized mice in the presence of irradiated splenocytes and flagellin a or flagellin $\mathrm{b}$. The levels of IL-17 in the supernatants of the immunized T cells were significantly higher than those of control T cells $(P<0.05$, Figures $7(\mathrm{a})$ and $7(\mathrm{~b}))$. The presence of the anti-CD4 monoclonal antibody during coculture returned the IL-17 levels as those of the control $\mathrm{T}$ cells, further indicating that $\mathrm{CD} 4^{+} \mathrm{T}$ cells are the predominant source of IL-17 in this system (Figures 7(a) and 7(b)). The IL-17 levels in the presence of the anti-CD8 monoclonal antibody during coculture had no significant difference between each group (Figures $7(\mathrm{a})$ and $7(\mathrm{~b}) ; P>0.05)$. IL-17 production by flagellin a- or flagellin b-immunized $\mathrm{T}$ cells when stimulated with the homologous antigen was significantly higher than that of $\mathrm{T}$ cells stimulated with heterologous antigen $(P<0.05$; Figures $7(\mathrm{c})$ and $7(\mathrm{~d})$ and Figures $7(\mathrm{e})$ and $7(\mathrm{f}))$. IL-17 production by flagellin a- or flagellin b-immunized $T$ cells when stimulated with heterologous antigen was significantly higher than that of the control T cells $(P<0.05$; Figures $7(\mathrm{c})$ and $7(\mathrm{~d})$ and Figures $7(\mathrm{e})$ and $7(\mathrm{f}))$. Flagellin a- or flagellin b-immunized $\mathrm{T}$ cells when stimulated with homologous or heterologous antigen in the presence of the anti-CD4 monoclonal antibody during coculture returned the IL-17 levels as those of the control $\mathrm{T}$ cells. There was no significant difference between the IL-17 levels of flagellin a or flagellin $b$ among cultures treated by either immunized $\mathrm{T}$ cells, anti-CD8 monoclonal antibody, or control $\operatorname{IgG}(P>0.05$; Figures $7(\mathrm{c})$ and $7(\mathrm{~d})$ and Figures $7(\mathrm{e})$ and $7(\mathrm{f}))$. $\mathrm{T}$ cell proliferation and IL-17 secretion response assays were confirmatory data showing the evidence for a heterologous $\mathrm{T}$ cell response among immunized flagellin a or b mice indicating an active clonal expansion and a neutrophil response that lead to higher survival (protective) rates among immunized mice than control mice.

3.7. Bivalent Flagellin Vaccine Decreased P. aeruginosa Strain Burden. In order to evaluate the protective efficacy of bivalent flagellin vaccine, we determined the bacteria number in the lung, liver, blood, and spleen of infected immunized mice. Immunization with bivalent flagellin reduced the PAK and PAO1 strain burden in the lung, liver, blood, and spleen compared with mice injected with PBS $(P<0.01$; Figures $8(\mathrm{a}), 8(\mathrm{~b}), 8(\mathrm{c})$, and $8(\mathrm{~d}))$. Immunization with flagellin a significantly decreased homologous strain PAK burden in the main organs and blood compared with the heterologous strain PAO1 burden $(P<0.05$; Figures $8(\mathrm{a}), 8(\mathrm{~b}), 8(\mathrm{c})$, and $8(\mathrm{~d}))$. Immunization with flagellin a significantly decreased homologous strain PAO1 burden in the main organs and blood compared with heterologous strain PAK burden $(P<0.05$; Figures $8(a), 8(b)$, $8(\mathrm{c})$, and $8(\mathrm{~d}))$. 


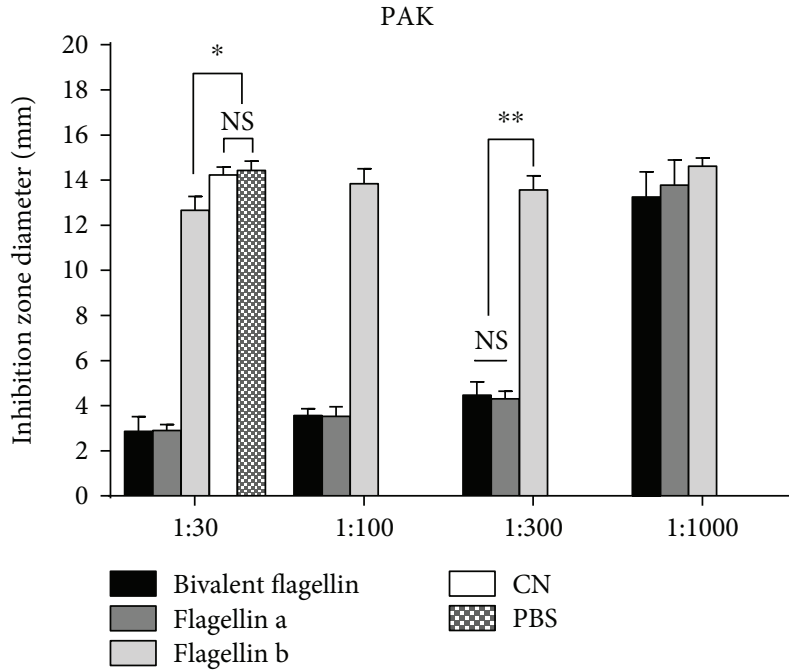

(a)

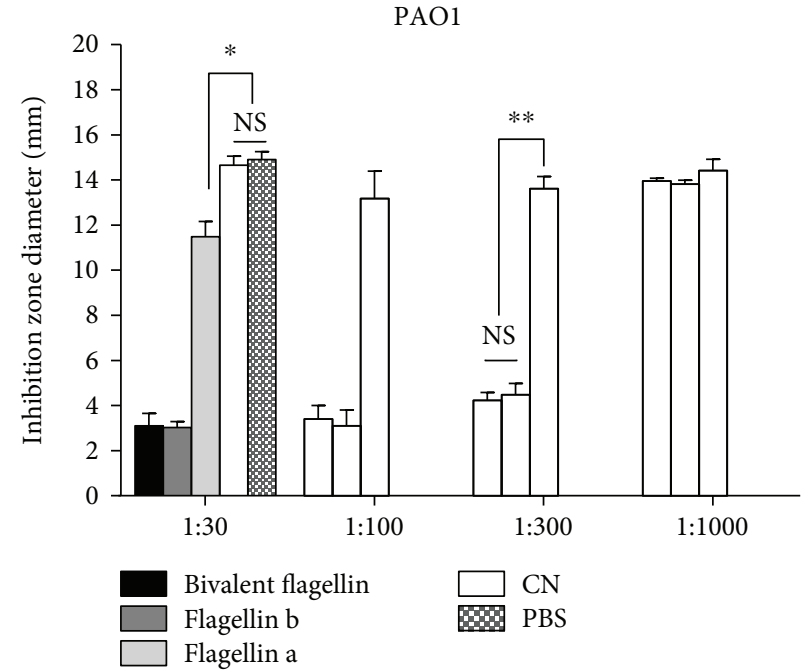

(b)

FIgURE 4: Assessment of motility inhibition of P. aeruginosa strains PAK (a) and PAO1 (b) by different dilutions of sera from bivalent flagellin-, flagellin a-, or flagellin b-immunized mice. Motility agar plates are prepared with diluted antibodies in each well prior to stabbing each well with fresh overnight bacterial cultures. The mean diameters of $P$. aeruginosa strains were measured in millimeters $($ mean $+\mathrm{SD})$. Values presented as mean of triplicate independent experiments \pm SD. ${ }^{*} P<0.05$ and ${ }^{* *} P<0.01$. NS $=$ not significant. $\mathrm{CS}=$ control serum.

3.8. Neutrophil Recruitment to the Lungs of Bivalent FlagellinImmunized Mice. As IL-17 is a critical mediator for neutrophil recruitment to the lung, we evaluated the numbers of neutrophils recruited to the airways in immunized mice. As shown in Figures 9(a), 9(e), and 9(f), in bivalent flagellinimmunized mice, the number of BALF neutrophils and IL17 levels at $6 \mathrm{~h}$ after the challenge were significantly more than those of the controls $(P<0.05)$. At this point in time, the bacteria numbers in the BALF of bivalent flagellinimmunized were significantly lower than those of the controls $(P<0.05$, Figure $9(\mathrm{c}))$. IL-17 levels and neutrophil numbers in BALF of the flagellin a- or b-immunized mice obtained $6 \mathrm{~h}$ after homologous challenge were significantly higher than those in mice challenged with the heterologous strain $(P<0.05$; Figures 9(a), 9(e), and 9(f)). In flagellin aor b-immunized mice, IL-17 levels and neutrophil numbers in BALF obtained $6 \mathrm{~h}$ after challenge with the heterologous strain were significantly higher than those in nonimmunized mice $(P<0.05$; Figures 9(a), 9(e), and 9(f)). At this point in time, the heterologous strain numbers in the BALF of flagellin a- or b-immunized mice were significantly lower than those in mice challenged with the heterologous strain. $(P<0.05$, Figure $9(\mathrm{c}))$. At $18 \mathrm{~h}$ after bacterial challenge, the number of BALF neutrophils and bacterial CFU in bivalent flagellin-immunized mice was significantly lower than that of the controls $(P<0.05$; Figures $9(\mathrm{~b})$ and $9(\mathrm{~d}))$. IL-17 levels and neutrophil in BALF of the flagellin a- or b-immunized mice obtained $18 \mathrm{~h}$ after homologous challenge were significantly higher than those in mice challenged with the heterologous strain $(P<0.05$; Figures $9(\mathrm{~b}), 9(\mathrm{e})$, and $9(\mathrm{f}))$. At this point in time, the heterologous strain numbers in the BALF of flagellin a- or b-immunized mice were significantly lower than those in mice challenged with the heterologous strain. $(P<0.05$, Figure $9(\mathrm{~d}))$.
3.9. Effect of Neutralization of IL-17 on Protective Efficacy of Bivalent Flagellin Vaccine. To further assess the protective role of IL-17 in the bivalent flagellin vaccine efficacy, we investigated the effects of neutralization of IL-17 prior to lung challenge with $P$. aeruginosa strains. As shown in Figures 10 (a) and 10(b), mortality in the bivalent flagellinimmunized mice which received anti-IL-17 IgG was significantly higher than that given in the control IgG $(P<0.05)$. In flagellin a-immunized group, the survival rate decreased to $50 \%$ and $8.33 \%$ after receiving anti-IL-17 IgG when challenged with the strains PAK and PAO1, respectively (Figures $10(\mathrm{c})$ and $10(\mathrm{~d})$ ). In flagellin b-immunized group, the survival rate decreased to $41.66 \%$ and $0 \%$ after receiving anti-IL-17 IgG when challenged with the strains PAO1 and PAK, respectively (Figures 10(e) and 10(f)).

\section{Discussion}

Pulmonary infections due to $P$. aeruginosa have emerged as a serious challenge for medical therapy, mainly due to the paucity of new effective antibiotic classes and high morbidity and mortality [35]. This terrible situation has motivated attention in the vaccine, a possible approach to combat $P$. aeruginosa. In addition, the complex pathogenicity of $P$. aeruginosa and the diverse function of its virulence factors represent major obstacles to the development of effective universal vaccines [36]. For full-fledged protection against various $P$. aeruginosa infection, incorporation of innate and adaptive immune system is crucial. In lung tissue, a combination of opsonizing antibodies and inflammatory responses of the innate immune cell is mediated full-fledged protection against $P$. aeruginosa [34]. Thus, antigens in an effective vaccine against $P$. aeruginosa infections should induce both humoral and cellular immune responses. Although several $P$. aeruginosa 


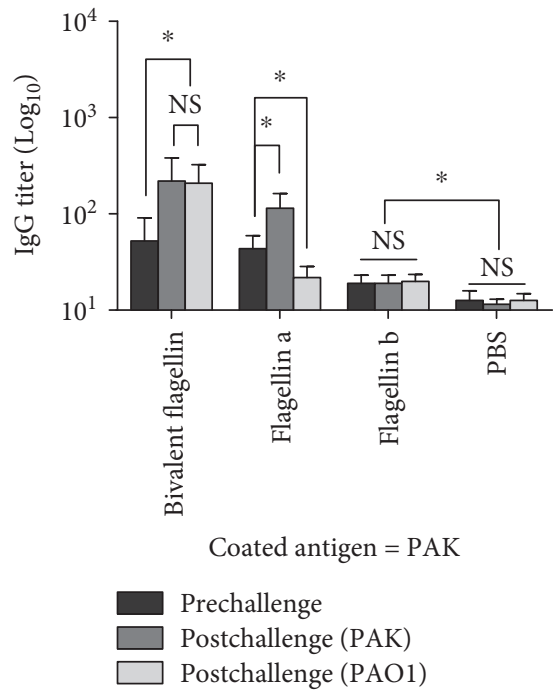

(a)

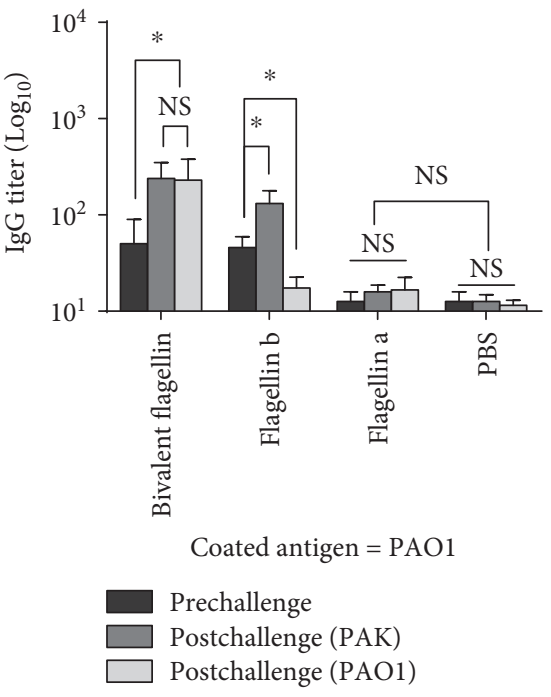

(b)

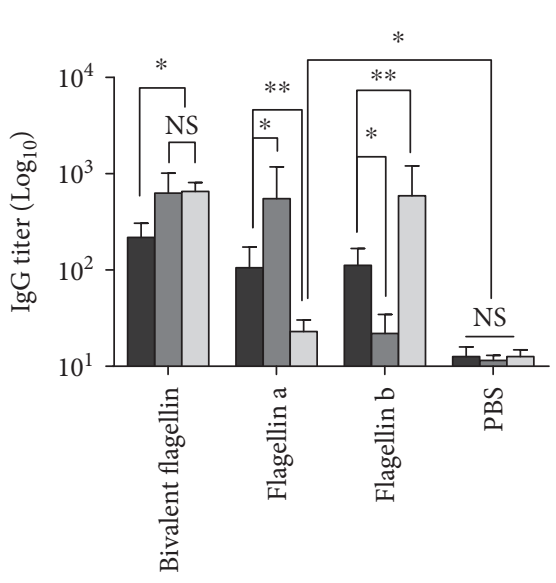

Coated antigen $=$ mixed flagellins

Prechallenge

Postchallenge (PAK)

Postchallenge (PAO1)

(c)

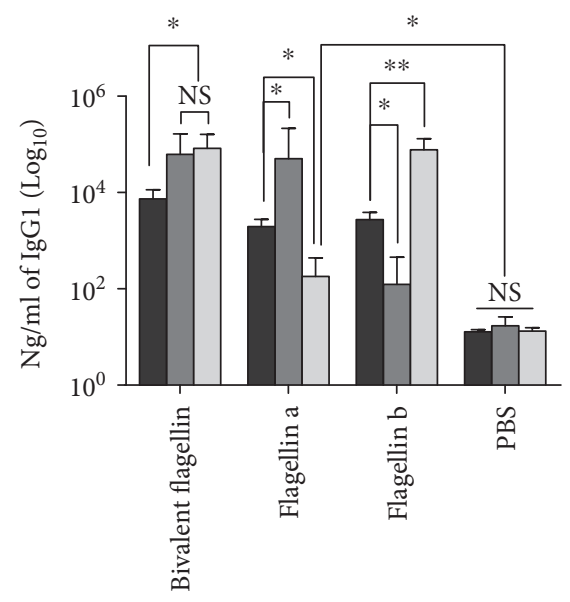

Coated antigen $=$ mixed flagellins

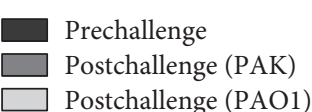

(d)

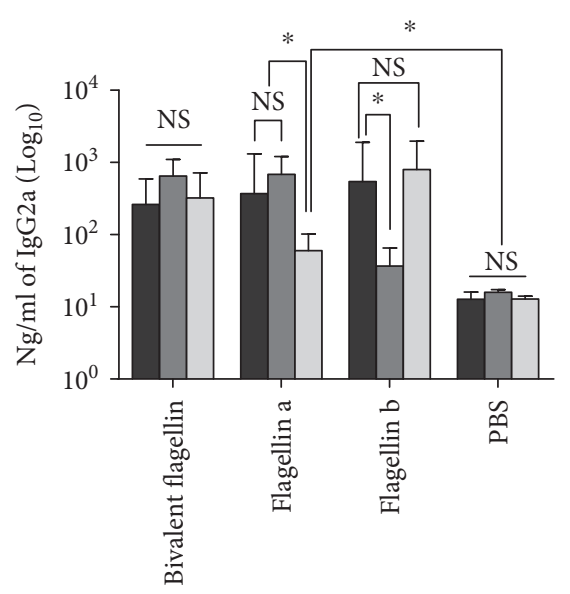

Coated antigen $=$ mixed flagellins

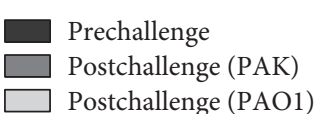

(e)

FIGURE 5: Effects of bivalent flagellin immunization on pre and postchallenge levels of serum total IgG against the whole cell of $P$. aeruginosa PAK (a), PAO1 (b), and mixed flagellins (c). The pre- and postchallenge serum IgG1 (d) and IgG2a (e) titers against mixed flagellins. Values are represented as mean \pm SD based on five mice in each group. ${ }^{*} P<0.05$ and ${ }^{* *} P<0.01$. NS = nonsignificance.

antigens have so far been evaluated as $P$. aeruginosa vaccine candidates, flagellin proteins hold a greatest promise because these $P$. aeruginosa components evoke in vivo immune responses which in turn promote opsonophagocytic activity [25]. They are also vital for $P$. aeruginosa survival during infection and are expressed by the majority of clinical $P$. aeruginosa strains [26]. Moreover, flagellin promotes marked increases in $\mathrm{T}$ and $\mathrm{B}$ lymphocyte recruitment to secondary lymphoid sites, increasing the likelihood of these cells encountering their specific antigen, and can also directly stimulate $\mathrm{CD}^{+}$and $\mathrm{CD} 8^{+} \mathrm{T}$ cells $[14,15]$.

Here, we have shown that bivalent flagellin vaccine provided significant homologous and heterologous protection against fatal $P$. aeruginosa pneumonia and it was associated with antiopsonophagocytic killing and antimotility activities as well as an effector IL-17 cytokine response. Indeed, the antiopsonophagocytic killing and antimotility activities provided by bivalent flagellin antiserum to blunt the pathogenesis and invasive progression of infection coupled with the effector cytokines of Th17 cells augmented a broader spectrum of protective activity against $P$. aeruginosa-induced fatal pneumonia. Evaluation of various aspects of mouse immune response and protective efficacy of the vaccine in a murine acute pneumonia model indicated robust protection against potentially lethal $P$. aeruginosa infections.

The cytokine secretion of splenic $\mathrm{T}$ cells indicated that bivalent flagellin could induce efficient Th17 type cytokines by antigen stimulation in combination with the findings that 


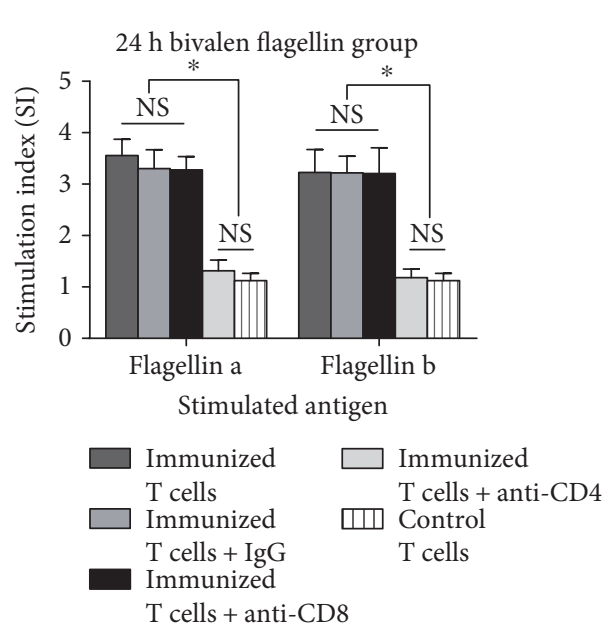

(a)

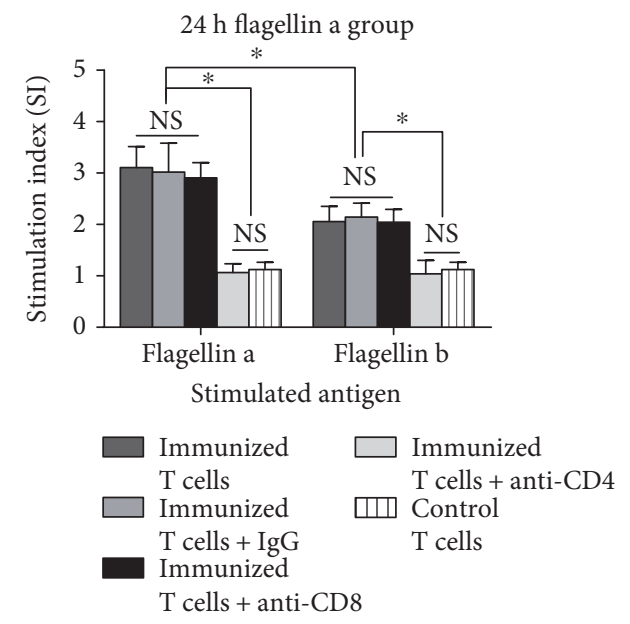

(c)

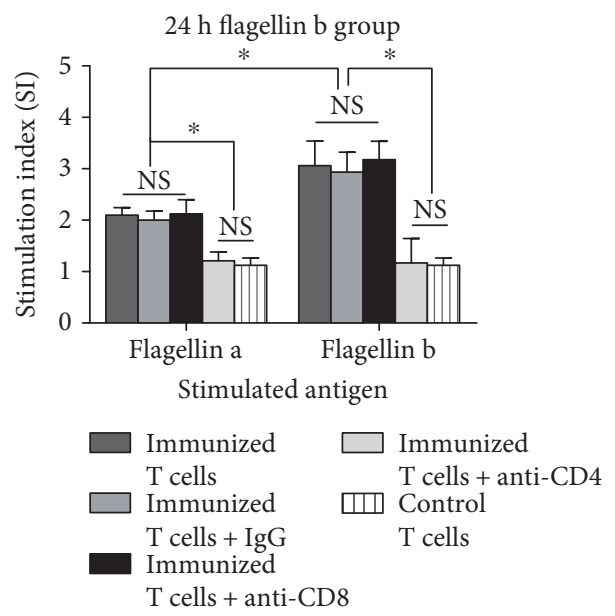

(e)

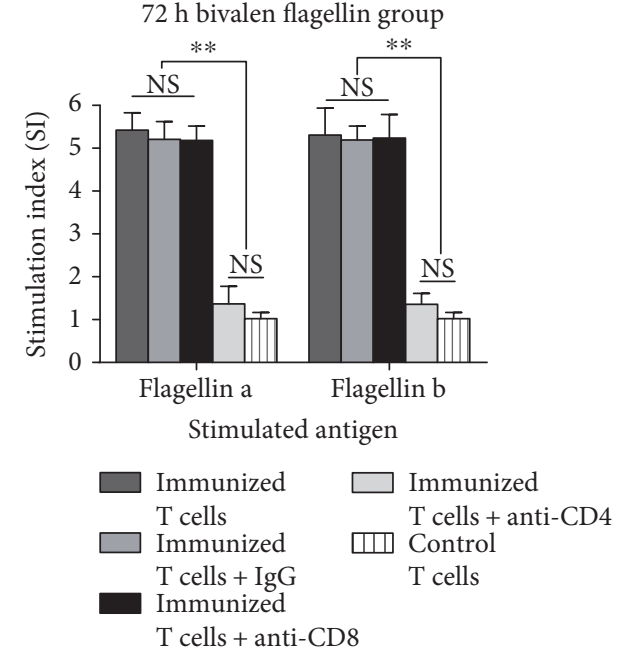

(b)

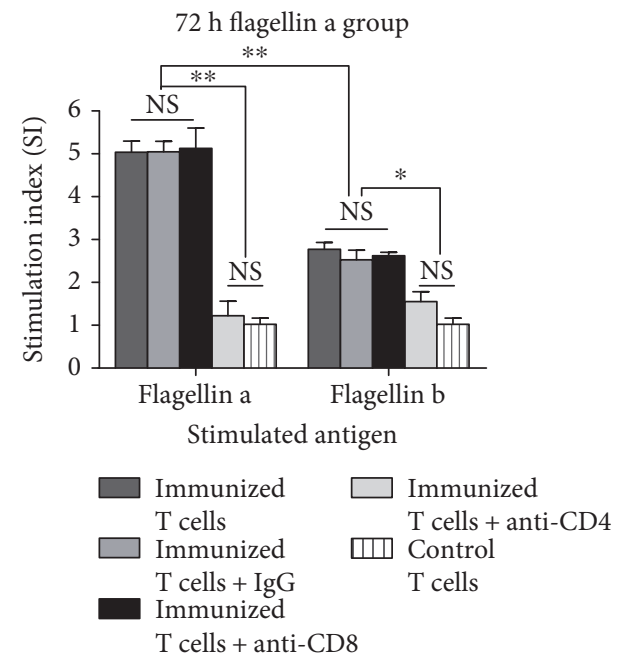

(d)

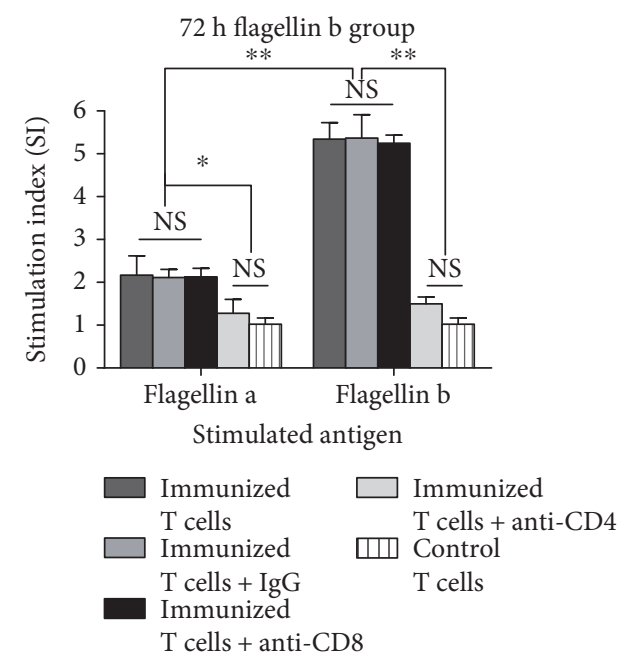

(f)

Figure 6: Proliferative assay of immune splenic T cells from bivalent flagellin ( $a, b)$, flagellin a (c, d), and flagellin b (e, f) stimulated with antigens in vitro for $24 \mathrm{~h}$ and $72 \mathrm{~h}$. Values are represented as mean $\pm \mathrm{SD}$ based on five mice in each group. ${ }^{*} P<0.05$ and ${ }^{* *} P<0.01$. NS = nonsignificance. 


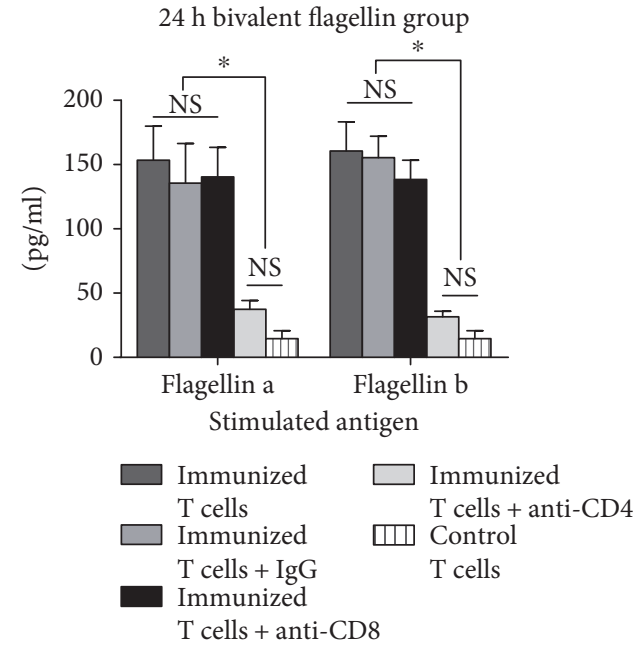

(a)

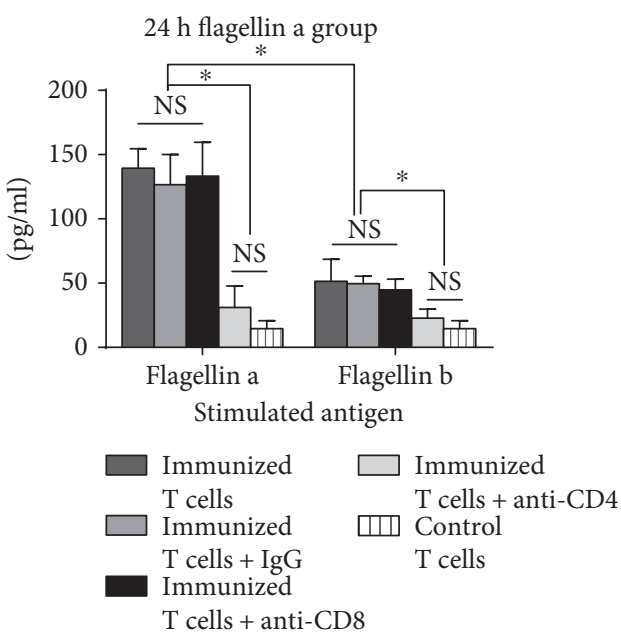

(c)

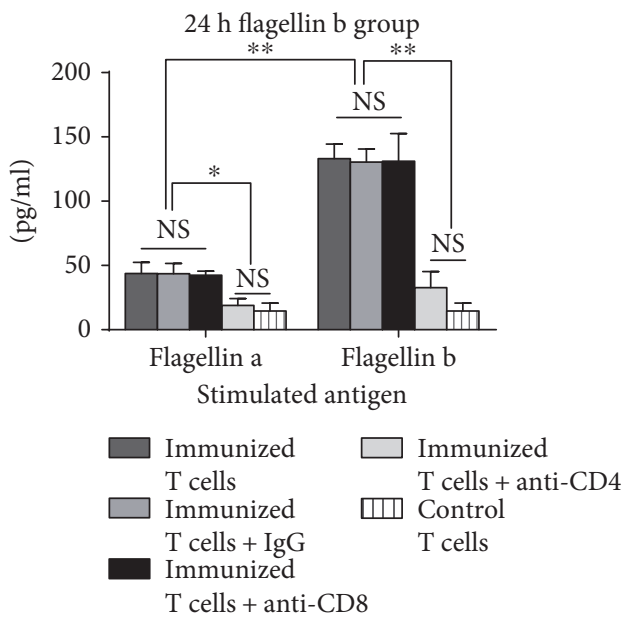

(e)

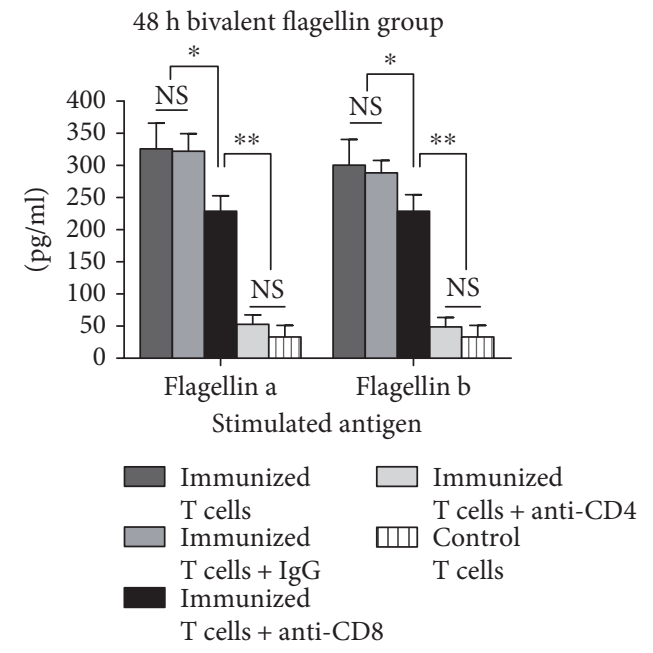

(b)

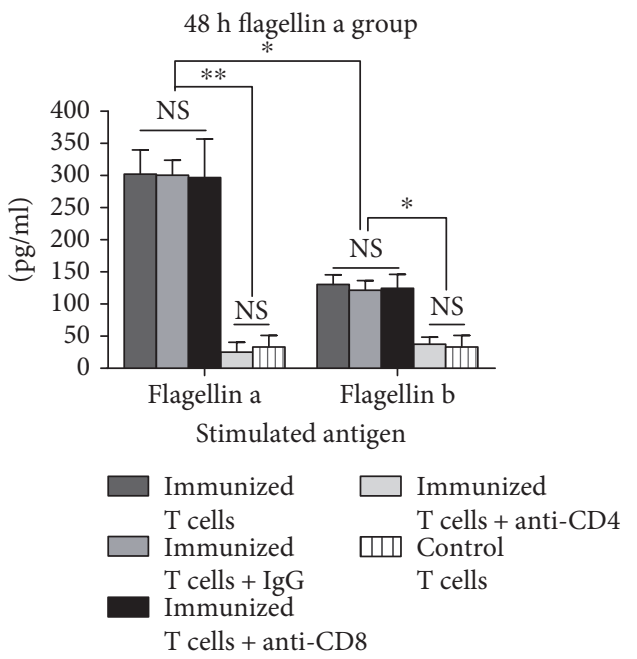

(d)

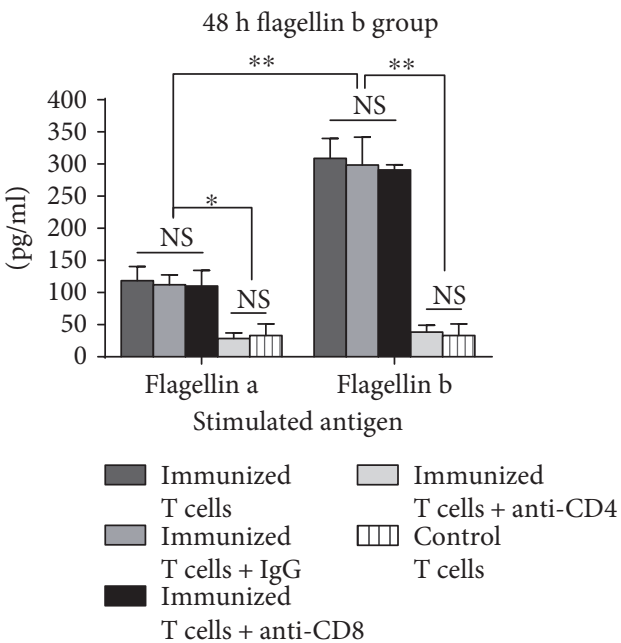

(f)

FIGURE 7: Effects of active immunization with bivalent flagellin on IL-17 production of immune splenic T cells from bivalent flagellin (a, b), flagellin a (c, d), and flagellin b $(e, f)$ at $24 \mathrm{~h}$ and $48 \mathrm{~h}$ after stimulation with flagellin a or flagellin $\mathrm{b}$. Values represented as mean \pm SD based on five mice in each group. ${ }^{*} P<0.05$ and ${ }^{* *} P<0.01$. NS $=$ nonsignificance. 


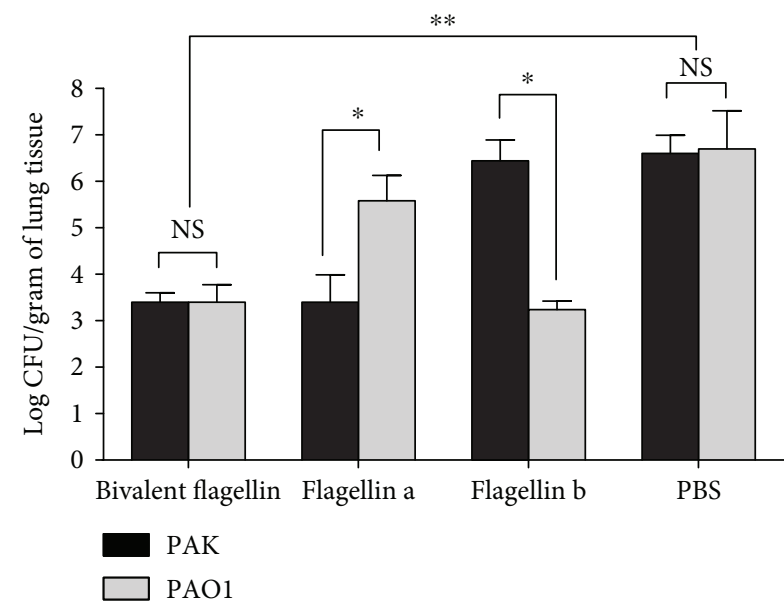

(a)

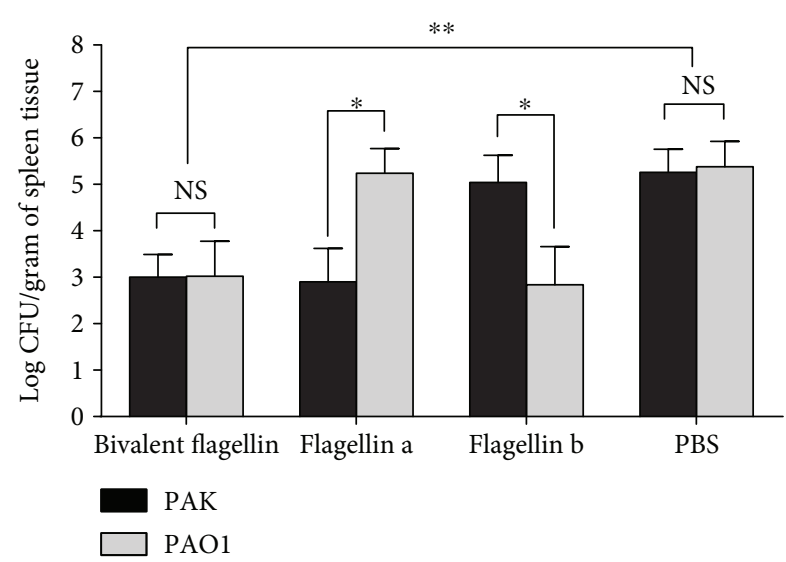

(c)

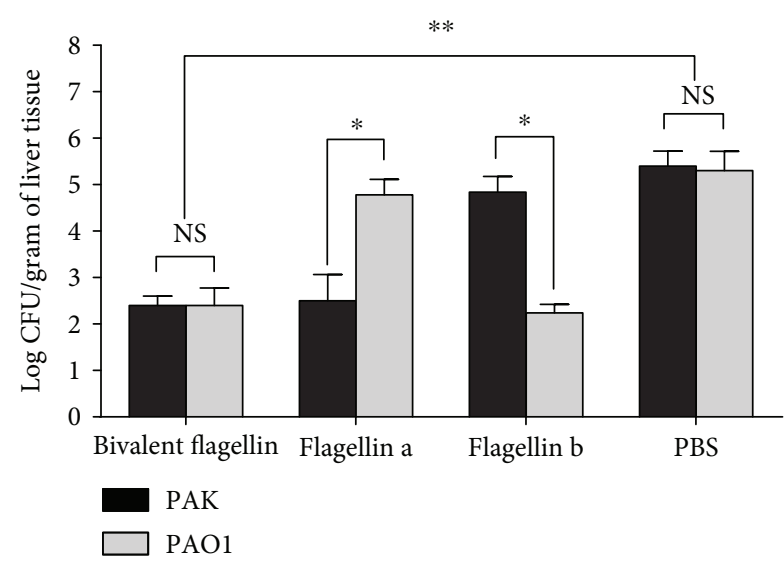

(b)

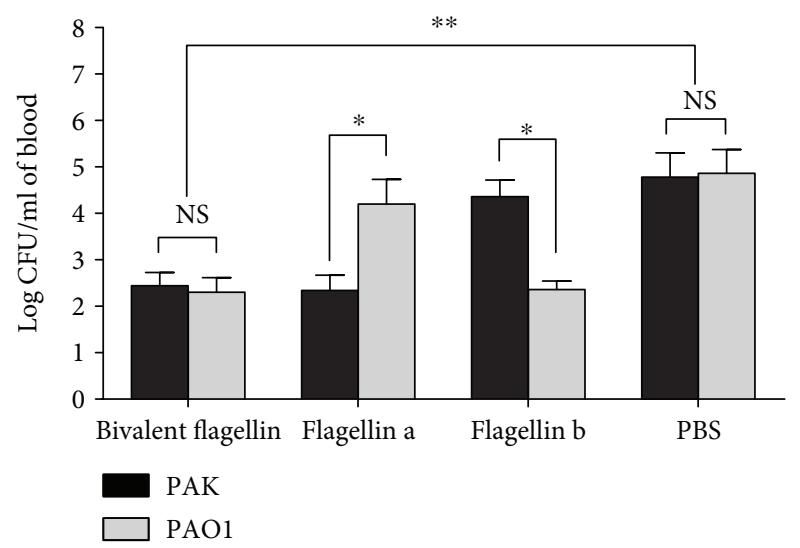

(d)

Figure 8: The effect of nasal immunization with bivalent flagellin, flagellin a, and flagellin $\mathrm{b}$ on the local and systemic spread of $P$. aeruginosa strains PAK and PAO1. Bacterial load was determined as CFUs (log) in the lung (a), liver (b), spleen (c), and blood (d). Values represented as mean \pm SD based on five mice in each group. ${ }^{*} P<0.05$ and ${ }^{* *} P<0.01$. NS $=$ nonsignificance.

$\operatorname{IgG1}$ and IgG2a subtypes in the serum of immunized mice further confirm that flagellin evokes the development of humoral and cell-mediated immune responses and acquires greater efficacy than monovalent flagellin to provide protection against different flagellated strains of $P$. aeruginosa. These data suggested that collaboration of $\mathrm{CD} 4^{+} \mathrm{T}$ cells with the capacity to produce IL-17 and opsonic antibodies is required for protective immunity against acute $P$. aeruginosa pneumonia $[37,38]$. The protective immune response following $P$. aeruginosa immunization of rats is associated with $\mathrm{CD}^{+}{ }^{+} \mathrm{T}$ cell-dependent immunity [39]. P. aeruginosa immunization of mice pulsed DCs protecting mice against pulmonary infection, depending on the presence of $\mathrm{CD}^{+}$ T cells [38].

It must so be mentioned that IL-17 was recently shown to be a critical factor in a vaccine that induced protection to $P$. aeruginosa [10]. IL-17 mainly mediates its immune regulatory function by promoting the production of antimicrobial peptides from lung epithelia or of proinflammatory cytokines and chemokines, which leads to the attraction of neutrophils and macrophages to the lung and the subsequently increased phagocytosis of bacteria and enhanced clearance of infection
$[9,10,40]$. Early increased neutrophil number in bivalent flagellin-immunized mouse lung tissue is associated with a rapid reduction of bacterial load in lung tissue as well as in homologous and heterologous protection. Our data suggest that $\mathrm{CD} 4^{+} \mathrm{T}$ cells may be one of the sources of IL-17 during acute pulmonary $P$. aeruginosa infection and could be a key component of full immunity to lung infection by this pathogen $[41,42]$. A recent study has shown that $\gamma \delta \mathrm{T}$ cells produced IL-17 in the lungs as early as $2 \mathrm{~h}$ after Bordetella pertussis infection [43]. The level of IL-17 increased $6 \mathrm{~h}$ after infection, demonstrating that acute pulmonary infection with $P$. aeruginosa rapidly induced IL-17 production in the lungs; this IL-17 may be involved in the innate immune response to the infection $[44,45]$.

Also, $\mathrm{T}$ cells from nasally immunized mice with liveattenuated $P$. aeruginosa vaccine show a high IL-17 levels after antigen stimulation and high number of $\mathrm{CD} 4^{+} \mathrm{IL}-$ $17^{+} \mathrm{Th} 17$ cells in the spleen at $6 \mathrm{~h}$ after challenge and mediated protective immune responses [34]. Although the focus of studies examining IL-17 production has largely been on $\mathrm{CD} 4^{+} \alpha \beta \mathrm{T}$ cells, $\gamma \delta \mathrm{T}$ cells have also been shown to be a potent source of IL-17 and, in some cases, produce more 


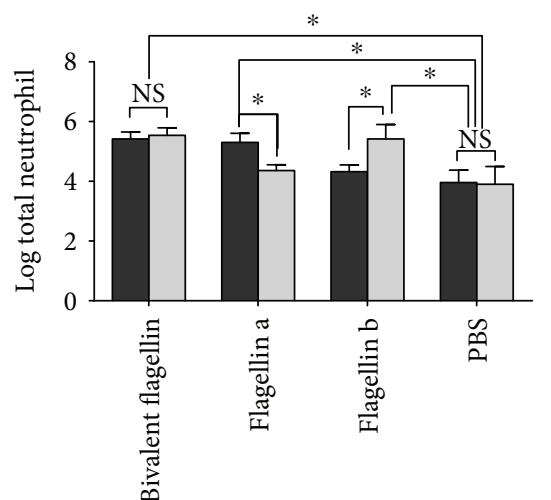

$6 \mathrm{~h}$

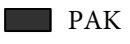

$\square$ PAOI

(a)

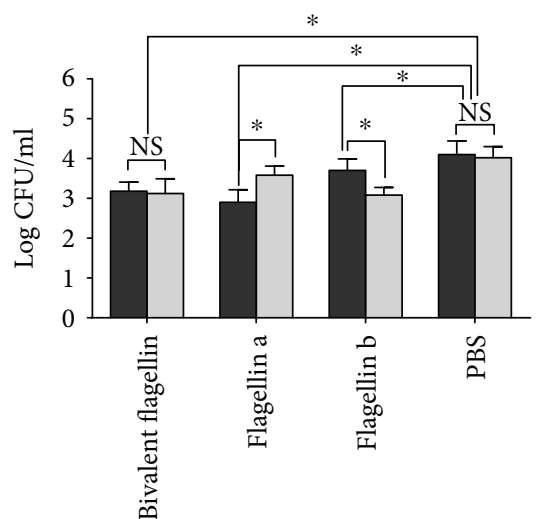

$6 \mathrm{~h}$

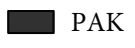

$\square$ PAO1

(c)

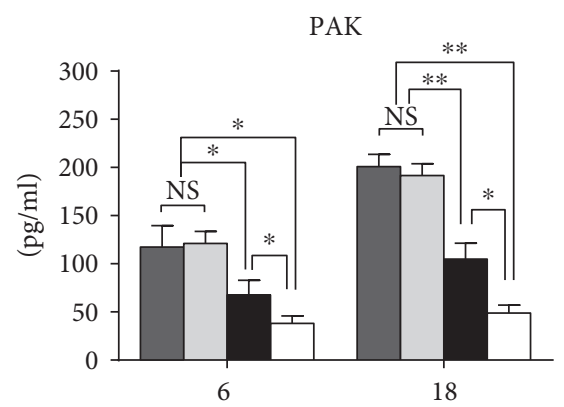

(h)

Bivalent flagellin Flagellin a

(e)

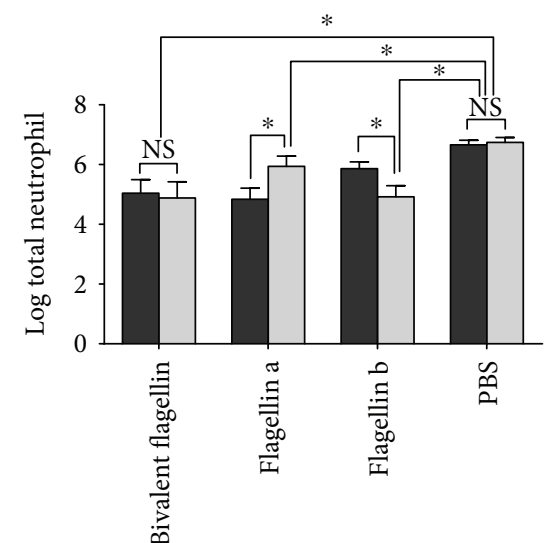

$18 \mathrm{~h}$

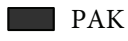

$\square$ PAO1

(b)

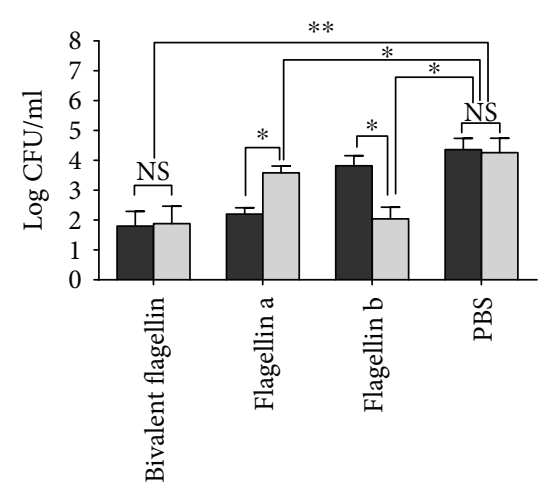

$18 \mathrm{~h}$

PAK

$\square$ PAO1

(d)

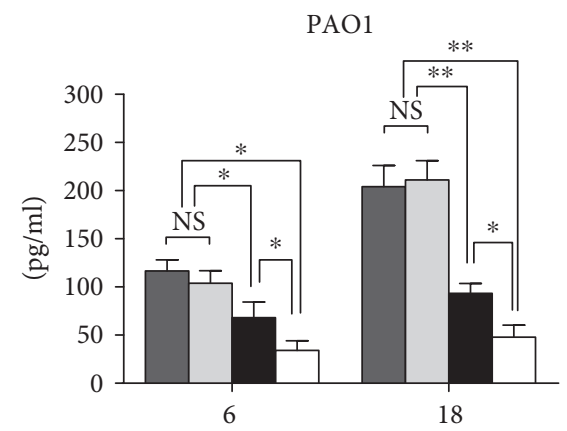

(h)

Bivalent flagellin Flagellin b Flagellin a $\square$ PBS

(f)

Figure 9: Total BALF neutrophils at $6 \mathrm{~h}(\mathrm{a})$ and $18 \mathrm{~h}(\mathrm{~b})$ after infection of immune and nonimmune mice with P. aeruginosa strains PAK and PAO1. The bacterial CFU in BALF at $6 \mathrm{~h} \mathrm{(a)} \mathrm{and} 18 \mathrm{~h} \mathrm{(b)} \mathrm{after} \mathrm{infection} \mathrm{of} \mathrm{immune} \mathrm{and} \mathrm{nonimmune} \mathrm{mice} \mathrm{with} \mathrm{PAK} \mathrm{(e)} \mathrm{and} \mathrm{PAO1} \mathrm{(f).} \mathrm{IL-17}$ level in BALF at $6 \mathrm{~h}(\mathrm{a})$ and $18 \mathrm{~h}$ (b) after infection of immune and nonimmune mice with PAK (e) and PAO1 (f). Values represented as mean \pm SD based on five mice in each group. ${ }^{*} P<0.05$ and ${ }^{* *} P<0.01$. NS $=$ nonsignificance. 


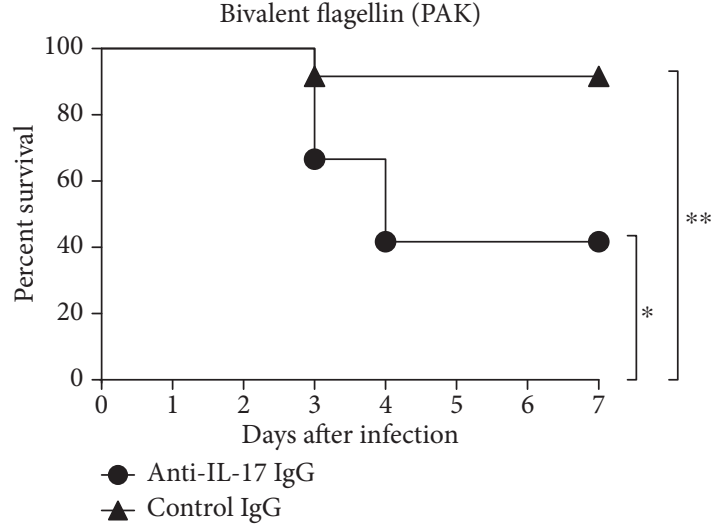

(a)

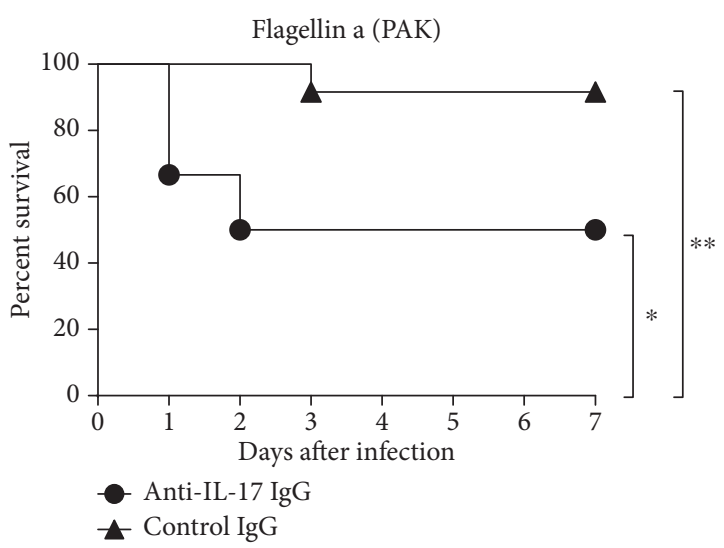

(c)

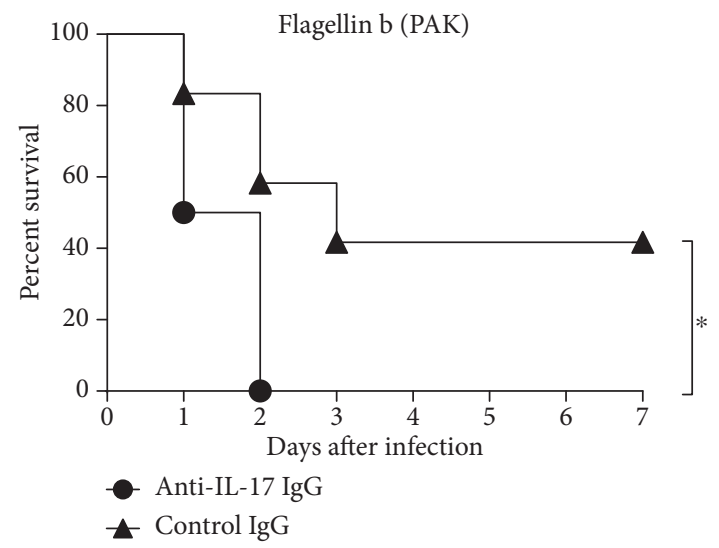

(e)

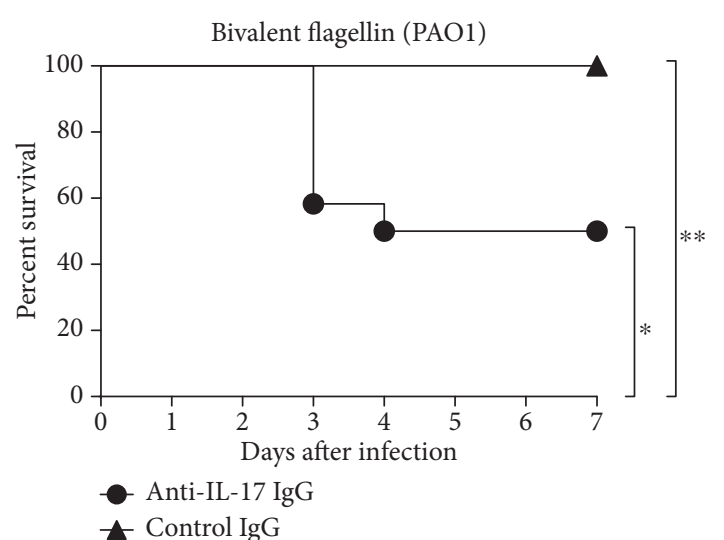

(b)

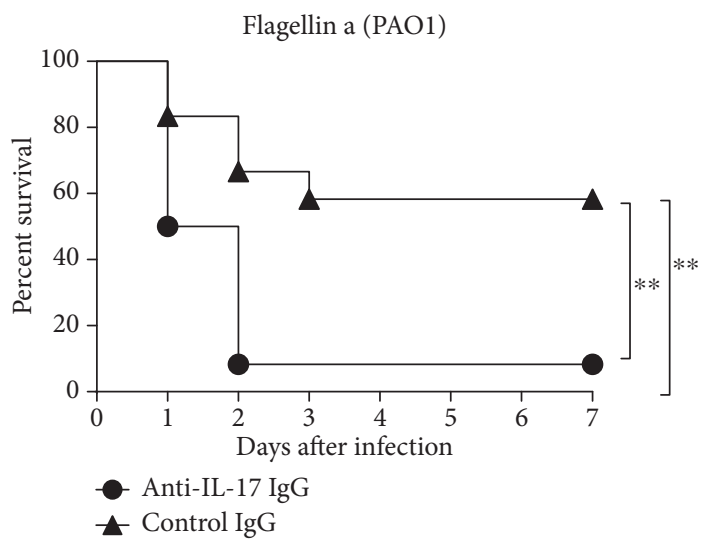

(d)

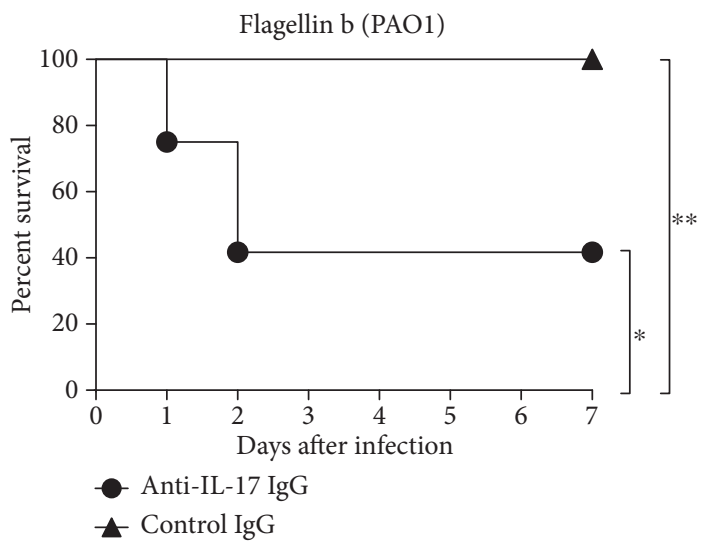

(f)

FIGURE 10: The role of IL-17 in vaccine based protection against $P$. aeruginosa strains. Bivalent flagellin- (a, b), flagellin a- (c, d), and flagellin b- (e, f) immunized mice ( $n=12$ mice/group) were given IL-17 IgG or control IgG for 3 consecutive days prior to challenge with $2 \times 10^{7}$ CFUs of $P$. aeruginosa strains PAO1 and PAK. ${ }^{*} P<0.05$ and ${ }^{* *} P<0.01$.

IL-17 than $\alpha \beta$ T cells [46-49]. Interestingly, it has been shown that Th17 cells increase after $8 \mathrm{~h}$ of infection with $P$. aeruginosa, and the level of IL-23 also increases in the acute pulmonary P. aeruginosa infection [44]. Recent studies suggest that IL-23 promotes the Th17 cell development from effector memory $\mathrm{CD}_{4}^{+}$cells. The major cell type in the lung responsible for the clearance of $P$. aeruginosa is the neutrophil $[9,50]$. Protection achieved in the killed P. aeruginosaimmunized animals was associated with $\mathrm{CD} 4^{+} \mathrm{IL}-17^{+} \mathrm{Th} 17$ and rapid requirement of neutrophil in the lung [51]. The lower bacterial burden in the liver, spleen, and blood showed that the antibodies to bivalent flagellin could systemically disrupt the dissemination of both $P$. aeruginosa stains in the liver and spleen via the blood by inhibition of bacterial motility at the site of infection, which is the principal mechanism of protection in the bloodstream infections following $P$. aeruginosa acute pneumonia model $[17,18,52]$. Although the antibodies against type $\mathrm{a}$ or $\mathrm{b}$ flagellin completely inhibited 
the motility of the homologous strain, they also had slight effects on the heterologous strain. The results of motility inhibition and opsonophagocytic activities indicated that the protective effect of antibodies against either type $a$ or $b$ flagellin is strain specific. Passive transfer of bivalent flagellin antisera protected mice against infection with both flagellated strains of $P$. aeruginosa. The achieved results are also consistent with several investigations that employed a burn wound model to show that passive immunization with antibodies raised to type $\mathrm{a}$ or $\mathrm{b}$ flagellin protects the infected mice with the homologous strain $[53,54]$. The protection provided by antibodies raised against flagellin is highly type specific, and the presence of antibodies to both flagellin types is critical. Thus, antibodies against bivalent flagellin showed a great activity against two different $P$. aeruginosa strains and did not interfere with the individual components for improving the opsonophagocytic killing and immobilizing different flagellated strains of $P$. aeruginosa. Hence, immunotherapy with the antibodies to bivalent flagellin is more successful in providing homologous and heterologous protection than therapy with antibodies raised to each monovalent type a or b flagellin. Also, immunization with our novel bivalent flagellin vaccine does not interfere with the individual components in improving survival or induction of protective antibodies. We acknowledge that our protective efficacy data are contrary to Campodonico et al. [23], who exposed that antibodies against type a or b flagellin had a low protective activity against the homologous strain and no activity against the heterologous strain. It seems feasible that the apparent data discrepancy might be explained by our approach using the fulllength type $\mathrm{a}$ and $\mathrm{b}$ flagellins as the target antigen of the study. In addition, Campodonico et al. separately examined the effects of type $a$ and $b$ flagellins but did not assess bivalent flagellin [23]. Our finding that antibodies against type $a$ or $b$ flagellin show high activity against homologous strains and low activity against a heterologous strain is contrary to a recent report [23], in which it was shown that antitype a flagellin antibodies against homologous $P$. aeruginosa strain have low opsonic killing activity and no killing activity. They also reported that type $b$ flagellin antibodies have no opsonic killing activity against either homologous or heterologous strain [23]. The apparent discrepancy may partially be explained by utilizing a mixture of full-length type $a$ and $b$ flagellins (containing $\mathrm{N}^{\prime}$ and $\mathrm{C}^{\prime}$-terminal domains) as immunogen, rather than flagellin subunits, and might account for the protective antibody response observed in our study. It is also worth mentioning that several reports have shown that both $\mathrm{N}^{\prime}$ - and $\mathrm{C}^{\prime}$-termini of flagellin protein have proinflammatory motifs $[55,56]$ and both trigger activation of the innate immune response via TLR5 that enhances protective inflammatory response and enhance recruitment of PMNs and facilitate Pseudomonas clearance postinfection [57]. Also, previous studies have shown that flagellin mutant bacteria elicited severe mucosal damage by a mechanism that also appears to involve the induction of apoptosis in the epithelial cells via inhibition of NF- $\kappa \mathrm{B}$ activation $[58,59]$. The TLR5 activation via flagellin may prevent bacteria to evade the host's innate immune responses and alter the level of tissue damage associated with late-stage bacterial infection [60].
After colonization, $P$. aeruginosa downregulates the expression levels of flagella to evade from the TLR5-mediated host's innate immune activation [61]. H. pylori may have evolved to express inactive flagellin to prevent activation of the TLR5mediated host's mucosal immunity, enabling persistent infection in the stomach epithelia [62]. Also, Campodonico et al.'s 2011 report demonstrated that conjugation of polymannuronic acid (PMA) to type a flagellin enhanced its immunogenicity via TLR5, indicating desirable protective antibodies were elicited and conserved mechanism of innate immune resistance to $P$. aeruginosa [63]. These observations have important implications for use of flagellin vaccine rather than flagella against flagellated pathogens. It seems that activation of TLR5 may induce the protective immunity against $P$. aeruginosa and decrease the risk to acquire infections from other flagellated bacteria that activate TLR5 [23, 63]. Lastly, we acknowledge that our findings are contrary to the 2010 report [23], which concluded that flagella are a better candidate to provide protection against infection because they observed that antitype a flagellin and antitype b flagellin antibodies have poor protective activity against homologous or heterologous $P$. aeruginosa strains. Several reports, however, have demonstrated that flagellininduced antibodies raised against $\mathrm{a}$ or $\mathrm{b}$ type flagellins have protective activity in various murine infection models $[53,64,65]$. Indeed, one novel feature of our approach is targeting both domains of full-length type a and b flagellins, as target antigen, protective anti-flagellin antibodies, as well as inducing $\mathrm{CD} 4^{+} \mathrm{IL}-17^{+}$Th17 cell response among immunized mice indicating an active clonal expansion and a neutrophil response that leads to higher survival (protective) rates among immunized mice than control mice.

It is also worth indicating that the active immunization with type a or b flagellin provided significantly protected mice against the heterologous strain than passive therapy with antibodies raised to type $a$ or $b$ flagellin. This phenomenon indicated that CD $4^{+} \mathrm{IL}-17^{+}$Th17 cell-mediated immune response might be responsible for the anti-infection activity afforded by the bivalent flagellin when antiopsonophagocytic killing and antimotility antibody levels were low. Also, in vivo $\mathrm{CD} 4^{+} \mathrm{T}$ cell depletion during immunization diminished the bivalent flagellin or type a or b flagellin vaccine-based protection against $P$. aeruginosa infection. However, the depletion of CD8 lymphocytes showed no abrogation of the antiinfection activity against the $P$. aeruginosa strains. The result of present study demonstrated the fact that both adaptive $\left(\mathrm{CD} 4^{+} \mathrm{T}\right.$ cells and antibodies) and innate (macrophage and neutrophil) effectors are required for protective immunity against $P$. aeruginosa strains. T cell proliferation and IL-17 secretion response assays were confirmatory data showing the evidence for a heterologous $\mathrm{T}$ cell response among immunized flagellin a or b mice indicating an active clonal expansion and a neutrophil response that leads to higher survival (protective) rates among immunized mice than control mice. A recent study demonstrated that protection mediated by PopB immunization against $P$. aeruginosa pneumonia is associated with increased IL-17 cytokine whereas antisera to PopB had neither opsonophagocytic nor anticytotoxic activity [9]. An important feature of a desirable vaccine for 
P. aeruginosa is the ability to induce IL-17 for rapid recruitment of neutrophils to the site of infection, where they can mediate opsonophagocytic bacterial killing. In a recent research [25], we demonstrated that bivalent flagellin vaccine could confer protection against burn wound infection with different flagellated strains of $P$. aeruginosa, by eliciting an effective humoral immune response, including improved opsonophagocytic killing and an immobilization of the pathogen at the wound site. Following burn injury, the failure of local and systemic cellular immune responses allows pathogenic bacteria to disseminate systemically from the site of infection to the bloodstream and easily escalate into sepsis. Thus, it seems that protective immune response against $P$. aeruginosa burn wound infection is mediated by opsonic antibodies. Hence, flagellin is a unique feature because of its ability to induce both cellular and humoral immune responses, which in turn provides protection against different $P$. aeruginosa infections.

Taken together, these results offer evidence that bivalent flagellin vaccine can confer protection against different flagellated strains of $P$. aeruginosa infection in a burn wound model by eliciting effective cellular and humoral immune responses, including induction of IL-17 and improved opsonophagocytic killing. Thus, reducing the systemic pathogen dissemination caused an increase in the survival of mice infected with $P$. aeruginosa. Moreover, these data further confirmed that targeting both types of flagellin with antibodies resulted in significantly improved efficacy in comparison with each monovalent antigen with the potential of broadening the coverage against $P$. aeruginosa strains which might not express one of the two targets. We maintain optimism that an effective $P$. aeruginosa bivalent flagellin vaccine may eventually be developed and tested in humans toward reducing the morbidity and mortality associated with lung infections caused by $P$. aeruginosa.

\section{Conflicts of Interest}

There are no conflicts of interest.

\section{References}

[1] P. H. Gilligan, "Infections in patients with cystic fibrosis: diagnostic microbiology update," Clinics in Laboratory Medicine, vol. 34, no. 2, pp. 197-217, 2014.

[2] N. Safdar, C. Dezfulian, H. R. Collard, and S. Saint, "Clinical and economic consequences of ventilator-associated pneumonia: a systematic review," Critical Care Medicine, vol. 33, no. 10, pp. 2184-2193, 2005.

[3] B. K. Chan, M. Sistrom, J. E. Wertz, K. E. Kortright, D. Narayan, and P. E. Turner, "Phage selection restores antibiotic sensitivity in MDR Pseudomonas aeruginosa," Scientific Reports, vol. 6, p. 26717, 2016.

[4] M. W. Douglas, K. Mulholland, V. Denyer, and T. Gottlieb, "Multi-drug resistant Pseudomonas aeruginosa outbreak in a burns unit-an infection control study," Burns : Journal of the International Society for Burn Injuries, vol. 27, no. 2, pp. 131-135, 2001.

[5] M. Mudau, R. Jacobson, N. Minenza et al., "Outbreak of multidrug resistant Pseudomonas aeruginosa bloodstream infection in the haematology unit of a South African academic hospital," PLoS One, vol. 8, no. 3, article e55985, 2013.

[6] G. B. Pier, "Promises and pitfalls of Pseudomonas aeruginosa lipopolysaccharide as a vaccine antigen," Carbohydrate Research, vol. 338, no. 23, pp. 2549-2556, 2003.

[7] E. T. Weimer, H. Lu, N. D. Kock, D. J. Wozniak, and S. B. Mizel, "A fusion protein vaccine containing OprF epitope 8, OprI, and type A and B flagellins promotes enhanced clearance of nonmucoid Pseudomonas aeruginosa," Infection and Immunity, vol. 77, no. 6, pp. 2356-2366, 2009.

[8] T. Sawa, T. L. Yahr, M. Ohara et al., "Active and passive immunization with the Pseudomonas $\mathrm{V}$ antigen protects against type III intoxication and lung injury," Nature Medicine, vol. 5, no. 4, pp. 392-398, 1999.

[9] W. Wu, J. Huang, B. Duan et al., “Th17-stimulating protein vaccines confer protection against Pseudomonas aeruginosa pneumonia," American Journal of Respiratory and Critical Care Medicine, vol. 186, no. 5, pp. 420-427, 2012.

[10] G. P. Priebe, R. L. Walsh, T. A. Cederroth et al., "IL-17 is a critical component of vaccine-induced protection against lung infection by lipopolysaccharide-heterologous strains of Pseudomonas aeruginosa," Journal of Immunology, vol. 181, no. 7, pp. 4965-4975, 2008.

[11] J. Haiko and B. Westerlund-Wikstrom, "The role of the bacterial flagellum in adhesion and virulence," Biology, vol. 2, no. 4, pp. 1242-1267, 2013.

[12] H. C. Ramos, M. Rumbo, and J. C. Sirard, "Bacterial flagellins: mediators of pathogenicity and host immune responses in mucosa," Trends in Microbiology, vol. 12, no. 11, pp. 509517, 2004.

[13] F. Hayashi, K. D. Smith, A. Ozinsky et al., "The innate immune response to bacterial flagellin is mediated by Toll-like receptor 5," Nature, vol. 410, no. 6832, pp. 1099-1103, 2001.

[14] S. K. Gupta, P. Bajwa, R. Deb, M. M. Chellappa, and S. Dey, "Flagellin a toll-like receptor 5 agonist as an adjuvant in chicken vaccines," Clinical and Vaccine Immunology : CVI, vol. 21, no. 3, pp. 261-270, 2014.

[15] S. Delavari, M. Sohrabi, M. S. Ardestani et al., "Pseudomonas aeruginosa flagellin as an adjuvant: superiority of a conjugated form of flagellin versus a mixture with a human immunodeficiency virus type 1 vaccine candidate in the induction of immune responses," Journal of Medical Microbiology, vol. 64, no. 11, pp. 1361-1368, 2015.

[16] E. T. Weimer, S. E. Ervin, D. J. Wozniak, and S. B. Mizel, "Immunization of young African green monkeys with OprF epitope 8-OprI-type A- and B-flagellin fusion proteins promotes the production of protective antibodies against nonmucoid Pseudomonasaeruginosa," Vaccine, vol. 27, no. 48, pp. 6762-6769, 2009.

[17] D. Drake and T. C. Montie, "Protection against Pseudomonas aeruginosa infection by passive transfer of anti-flagellar serum," Canadian Journal of Microbiology, vol. 33, no. 9, pp. 755-763, 1987.

[18] H. Ochi, H. Ohtsuka, S. Yokota et al., "Inhibitory activity on bacterial motility and in vivo protective activity of human monoclonal antibodies against flagella of Pseudomonas aeruginosa," Infection and Immunity, vol. 59, no. 2, pp. 550-554, 1991.

[19] M. J. Rosok, M. R. Stebbins, K. Connelly, M. E. Lostrom, and A. W. Siadak, "Generation and characterization of murine antiflagellum monoclonal antibodies that are protective 
against lethal challenge with Pseudomonas aeruginosa," Infection and Immunity, vol. 58, no. 12, pp. 3819-3828, 1990.

[20] B. Behrouz, M. Mahdavi, N. Amirmozafari et al., "Immunogenicity of Pseudomonas aeruginosa recombinant b-type fagellin as a vaccine candidate: protective efficacy in a murine burn wound sepsis model," Burns : Journal of the International Society for Burn Injuries, 2016.

[21] H. Ahmadi, B. Behrouz, G. Irajian, N. Amirmozafari, and S. Naghavi, "Bivalent flagellin immunotherapy protects mice against Pseudomonas aeruginosa infections in both acute pneumonia and burn wound models," Biologicals : Journal of the International Association of Biological Standardization, vol. 46, pp. 29-37, 2017.

[22] M. Saffari, S. Behbood, G. Irajian, A. Khorshidi, R. Moniri, and B. Behrouz, "Antibodies raised against divalent type b flagellin and pilin provide effective immunotherapy against Pseudomonas aeruginosa infection of mice with burn wounds," Biologicals : Journal of the International Association of Biological Standardization, vol. 45, pp. 20-26, 2017.

[23] V. L. Campodonico, N. J. Llosa, M. Grout, G. Doring, T. Maira-Litran, and G. B. Pier, "Evaluation of flagella and flagellin of Pseudomonas aeruginosa as vaccines," Infection and Immunity, vol. 78, no. 2, pp. 746-755, 2010.

[24] A. Kumar, L. D. Hazlett, and F. S. Yu, "Flagellin suppresses the inflammatory response and enhances bacterial clearance in a murine model of Pseudomonas aeruginosa keratitis," Infection and Immunity, vol. 76, no. 1, pp. 89-96, 2008.

[25] P. Laghaei, F. B. Hashemi, G. Irajian, F. Korpi, N. Amirmozafari, and B. Behrouz, "Immunogenicity and protective efficacy of Pseudomonas aeruginosa type a and b flagellin vaccines in a burned mouse model," Molecular Immunology, vol. 74, pp. 71-81, 2016.

[26] F. Korpi, G. Irajian, M. Mahadavi et al., "Active immunization with recombinant PilA protein protects against Pseudomonas aeruginosa infection in a mouse burn wound model," Journal of Microbiology and Biotechnology, 2015.

[27] G. Goudarzi, M. Sattari, M. H. Roudkenar, M. MontajabiNiyat, A. Zavaran-Hosseini, and K. Mosavi-Hosseini, "Cloning, expression, purification, and characterization of recombinant flagellin isolated from Pseudomonas aeruginosa," Biotechnology Letters, vol. 31, no. 9, pp. 1353-1360, 2009.

[28] B. Behrouz, N. Amirmozafari, N. Khoramabadi, M. Bahroudi, P. Legaee, and M. Mahdavi, "Cloning, expression, and purification of Pseudomonas aeruginosa flagellin, and characterization of the elicited anti-flagellin antibody," Iranian Red Crescent Medical Journal, vol. 18, no. 6, article e28271, 2016.

[29] A. DiGiandomenico, J. Rao, K. Harcher et al., "Intranasal immunization with heterologously expressed polysaccharide protects against multiple Pseudomonas aeruginosa infections," Proceedings of the National Academy of Sciences of the United States of America, vol. 104, no. 11, pp. 46244629, 2007.

[30] S. Farajnia, S. N. Peerayeh, A. Tanomand et al., "Protective efficacy of recombinant exotoxin A-flagellin fusion protein against Pseudomonas aeruginosa infection," Canadian Journal of Microbiology, vol. 61, no. 1, pp. 60-64, 2015.

[31] F. Yang, J. Gu, L. Yang et al., "Protective efficacy of the trivalent Pseudomonas aeruginosa vaccine candidate PcrV-OprIHcp1 in murine pneumonia and burn models," Scientific Reports, vol. 7, no. 1, p. 3957, 2017.

[32] A. Kamei, W. Wu, D. C. Traficante et al., "Collaboration between macrophages and vaccine-induced $\mathrm{CD}^{+} \mathrm{T}$ cells confers protection against lethal Pseudomonas aeruginosa pneumonia during neutropenia," The Journal of Infectious Diseases, vol. 207, no. 1, pp. 39-49, 2013.

[33] D. R. Chung, D. L. Kasper, R. J. Panzo et al., "CD4 ${ }^{+}$T cells mediate abscess formation in intra-abdominal sepsis by an IL-17-dependent mechanism," Journal of Immunology, vol. 170, no. 4, pp. 1958-1963, 2003.

[34] Y. Li, Z. Wang, X. Liu, J. Tang, B. Peng, and Y. Wei, "X-ray irradiated vaccine confers protection against pneumonia caused by Pseudomonas aeruginosa," Scientific Reports, vol. 6, p. 18823, 2016.

[35] J. B. Lyczak, C. L. Cannon, and G. B. Pier, "Establishment of Pseudomonas aeruginosa infection: lessons from a versatile opportunist," Microbes and Infection/Institut Pasteur, vol. 2, no. 9, pp. 1051-1060, 2000.

[36] I. A. Holder, "Pseudomonas immunotherapy: a historical overview," Vaccine, vol. 22, no. 7, pp. 831-839, 2004.

[37] L. D. Hazlett, S. A. McClellan, X. L. Rudner, and R. P. Barrett, "The role of Langerhans cells in Pseudomonas aeruginosa infection," Investigative Ophthalmology \& Visual Science, vol. 43, no. 1, pp. 189-197, 2002.

[38] S. Worgall, T. Kikuchi, R. Singh, K. Martushova, L. Lande, and R. G. Crystal, "Protection against pulmonary infection with Pseudomonas aeruginosa following immunization with $P$. aeruginosa-pulsed dendritic cells," Infection and Immunity, vol. 69, no. 7, pp. 4521-7, 2001.

[39] M. L. Dunkley, R. L. Clancy, and A. W. Cripps, "A role for CD4+ $\mathrm{T}$ cells from orally immunized rats in enhanced clearance of Pseudomonas aeruginosa from the lung," Immunology, vol. 83, no. 3, pp. 362-369, 1994.

[40] S. Shahrara, S. R. Pickens, A. M. Mandelin 2nd et al., "IL-17mediated monocyte migration occurs partially through CC chemokine ligand $2 /$ monocyte chemoattractant protein-1 induction," Journal of Immunology, vol. 184, no. 8, pp. 44794487, 2010.

[41] S. Aggarwal, N. Ghilardi, M. H. Xie, F. J. de Sauvage, and A. L. Gurney, "Interleukin-23 promotes a distinct CD4 T cell activation state characterized by the production of interleukin-17," The Journal of Biological Chemistry, vol. 278, no. 3, pp. 1910-1914, 2003.

[42] N. J. Kotloski, D. T. Nardelli, S. H. Peterson et al., "Interleukin23 is required for development of arthritis in mice vaccinated and challenged with Borrelia species," Clinical and Vaccine Immunology : CVI, vol. 15, no. 8, pp. 1199-1207, 2008.

[43] A. Misiak, M. M. Wilk, M. Raverdeau, and K. H. Mills, "IL-17-producing innate and pathogen-specific tissue resident memory $\gamma \delta$ T cells expand in the lungs of Bordetella pertussisinfected mice," Journal of Immunology, vol. 198, no. 1, pp. 363-374, 2017.

[44] J. Liu, Y. Feng, K. Yang et al., "Early production of IL-17 protects against acute pulmonary Pseudomonas aeruginosa infection in mice," FEMS Immunology and Medical Microbiology, vol. 61, no. 2, pp. 179-188, 2011.

[45] T. Pan, R. Tan, M. Li et al., "IL17-producing $\gamma \delta$ T cells may enhance humoral immunity during pulmonary Pseudomonas aeruginosa infection in mice," Frontiers in Cellular and Infection Microbiology, vol. 6, p. 170, 2016.

[46] E. Lockhart, A. M. Green, and J. L. Flynn, "IL-17 production is dominated by $\gamma \delta$ T cells rather than CD 4 T cells during mycobacterium tuberculosis infection," Journal of Immunology, vol. 177, no. 7, pp. 4662-4669, 2006. 
[47] K. Shibata, H. Yamada, H. Hara, K. Kishihara, and Y. Yoshikai, "Resident $\mathrm{V} \delta 1^{+} \gamma \delta \mathrm{T}$ cells control early infiltration of neutrophils after Escherichia coli infection via IL-17 production," Journal of Immunology, vol. 178, no. 7, pp. 4466-4472, 2007.

[48] R. K. Braun, C. Ferrick, P. Neubauer et al., "IL-17 producing $\gamma \delta$ $\mathrm{T}$ cells are required for a controlled inflammatory response after bleomycin-induced lung injury," Inflammation, vol. 31, no. 3, pp. 167-179, 2008.

[49] C. L. Roark, P. L. Simonian, A. P. Fontenot, W. K. Born, and R. L. O'Brien, " $\gamma \delta$ T cells: an important source of IL-17," Current Opinion in Immunology, vol. 20, no. 3, pp. 353-357, 2008.

[50] R. T. Sadikot, T. S. Blackwell, J. W. Christman, and A. S. Prince, "Pathogen-host interactions in Pseudomonas aeruginosa pneumonia," American Journal of Respiratory and Critical Care Medicine, vol. 171, no. 11, pp. 1209-1223, 2005.

[51] A. Buret, M. L. Dunkley, G. Pang, R. L. Clancy, and A. W. Cripps, "Pulmonary immunity to Pseudomonas aeruginosa in intestinally immunized rats roles of alveolar macrophages, tumor necrosis factor alpha, and interleukin-1 alpha," Infection and Immunity, vol. 62, no. 12, pp. 5335-5343, 1994.

[52] D. Drake and T. C. Montie, "Flagella, motility and invasive virulence of Pseudomonas aeruginosa," Journal of General Microbiology, vol. 134, no. 1, pp. 43-52, 1988.

[53] L. F. Neville, Y. Barnea, O. Hammer-Munz et al., "Antibodies raised against $\mathrm{N}^{\prime}$-terminal Pseudomonas aeruginosa flagellin prevent mortality in lethal murine models of infection," International Journal of Molecular Medicine, vol. 16, no. 1, pp. 165-171, 2005.

[54] Y. Barnea, Y. Carmeli, E. Gur et al., "Efficacy of antibodies against the $\mathrm{N}$-terminal of Pseudomonas aeruginosa flagellin for treating infections in a murine burn wound model," Plastic and Reconstructive Surgery, vol. 117, no. 7, pp. 2284-2291, 2006.

[55] K. D. Smith, E. Andersen-Nissen, F. Hayashi et al., "Toll-like receptor 5 recognizes a conserved site on flagellin required for protofilament formation and bacterial motility," Nature Immunology, vol. 4, no. 12, pp. 1247-1253, 2003.

[56] K. G. Murthy, A. Deb, S. Goonesekera, C. Szabo, and A. L. Salzman, "Identification of conserved domains in Salmonella muenchen flagellin that are essential for its ability to activate TLR5 and to induce an inflammatory response In Vitro," The Journal of Biological Chemistry, vol. 279, no. 7, pp. 56675675, 2004.

[57] R. Ramphal, V. Balloy, J. Jyot, A. Verma, M. Si-Tahar, and M. Chignard, "Control of Pseudomonas aeruginosa in the lung requires the recognition of either lipopolysaccharide or flagellin," Journal of Immunology, vol. 181, no. 1, pp. 586-592, 2008.

[58] M. Vijay-Kumar, H. Wu, R. Jones et al., "Flagellin suppresses epithelial apoptosis and limits disease during enteric infection," The American Journal of Pathology, vol. 169, no. 5, pp. 1686-1700, 2006.

[59] A. B. Molofsky, B. G. Byrne, N. N. Whitfield et al., "Cytosolic recognition of flagellin by mouse macrophages restricts Legionella pneumophila infection," The Journal of Experimental Medicine, vol. 203, no. 4, pp. 1093-1104, 2006.

[60] S. Saha, F. Takeshita, T. Matsuda et al., "Blocking of the TLR5 activation domain hampers protective potential of flagellin DNA vaccine," Journal of Immunology, vol. 179, no. 2, pp. 1147-1154, 2007.
[61] T. S. Murray, M. Egan, and B. I. Kazmierczak, "Pseudomonas aeruginosa chronic colonization in cystic fibrosis patients," Current Opinion in Pediatrics, vol. 19, no. 1, pp. 83-88, 2007.

[62] E. Andersen-Nissen, K. D. Smith, R. Bonneau, R. K. Strong, and A. Aderem, "A conserved surface on Toll-like receptor 5 recognizes bacterial flagellin," The Journal of Experimental Medicine, vol. 204, no. 2, pp. 393-403, 2007.

[63] V. L. Campodonico, N. J. Llosa, L. V. Bentancor, T. MairaLitran, and G. B. Pier, "Efficacy of a conjugate vaccine containing polymannuronic acid and flagellin against experimental Pseudomonas aeruginosa lung infection in mice," Infection and Immunity, vol. 79, no. 8, pp. 3455-3464, 2011.

[64] N. Sabharwal, S. Chhibber, and K. Harjai, "New possibility for providing protection against urinary tract infection caused by Pseudomonas aeruginosa by non-adjuvanted flagellin ' $\mathrm{b}$ ' induced immunity," Immunology Letters, vol. 162, no. 2, Part B, pp. 229-238, 2014.

[65] N. Sabharwal, S. Chhibber, and K. Harjai, "Divalent flagellin immunotherapy provides homologous and heterologous protection in experimental urinary tract infections in mice," International Journal of Medical Microbiology: IJMM, vol. 306, no. 1, pp. 29-37, 2016. 


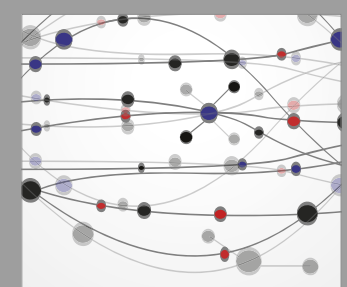

The Scientific World Journal
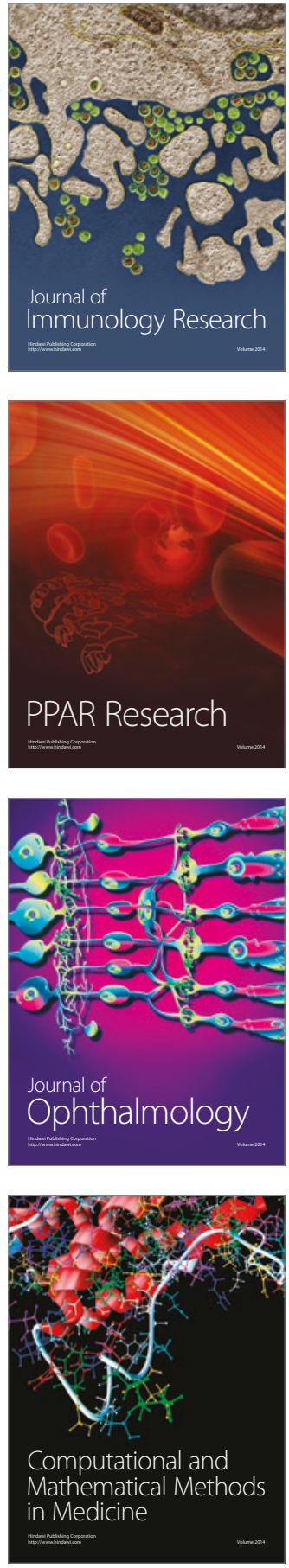

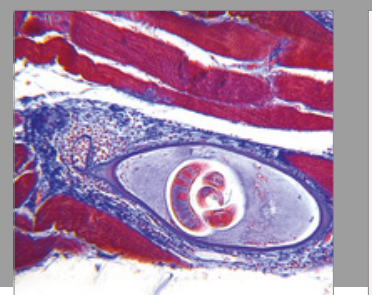

Gastroenterology Research and Practice
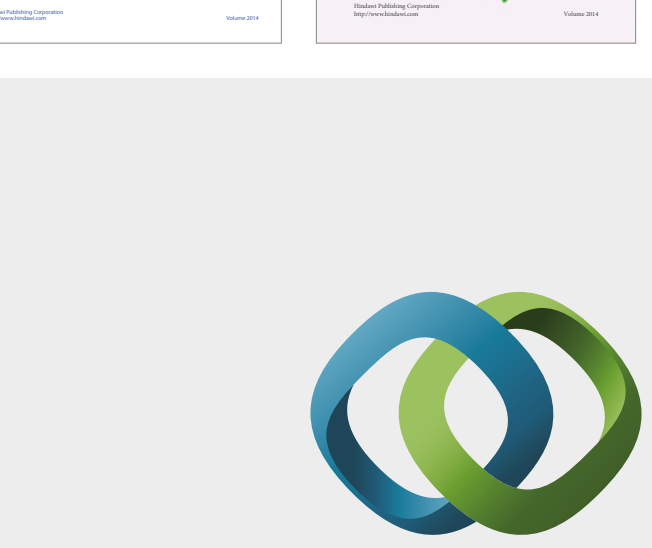

\section{Hindawi}

Submit your manuscripts at

https://www.hindawi.com
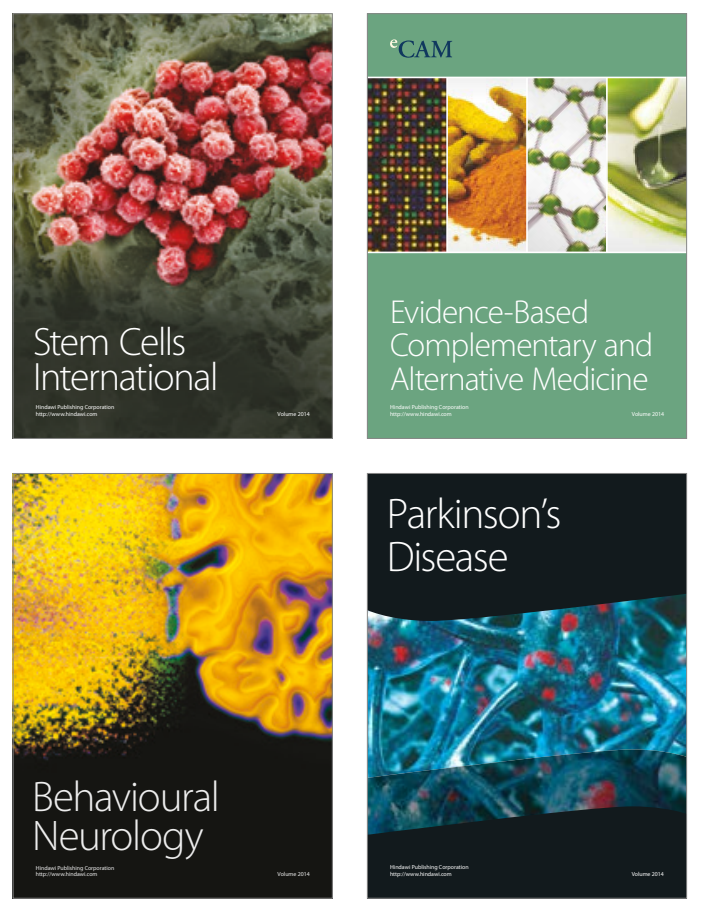
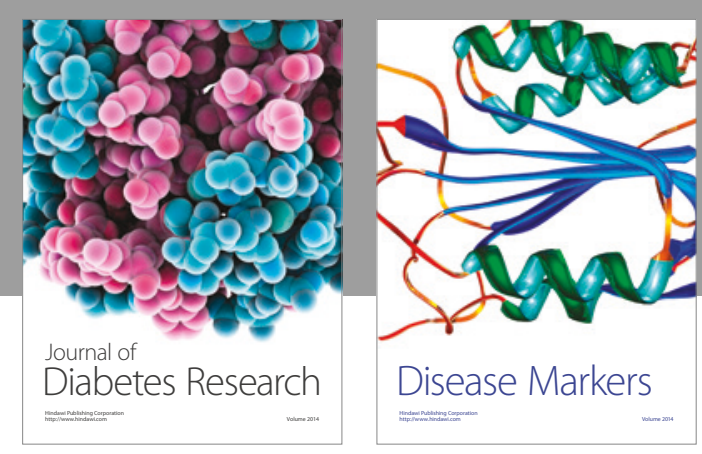

Disease Markers
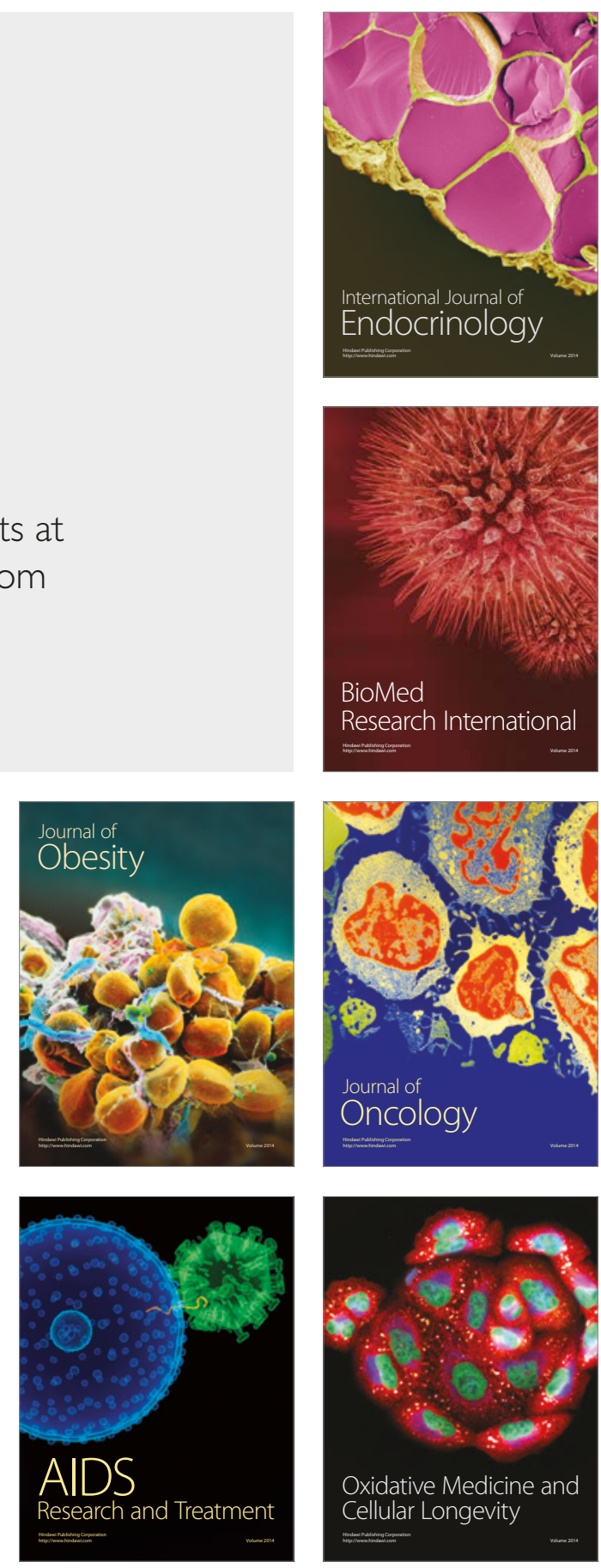